\title{
Nonlinear Flow Characteristics and Horizontal Well Pressure Transient Analysis for Low-Permeability Offshore Reservoirs
}

\author{
Jianchun Xu, Ruizhong Jiang, and Wenchao Teng \\ China University of Petroleum (East China), Qingdao 266580, China \\ Correspondence should be addressed to Jianchun Xu; illeyupc@gmail.com
}

Received 21 October 2014; Revised 29 January 2015; Accepted 13 February 2015

Academic Editor: Rosana Rodriguez-Lopez

Copyright ( 2015 Jianchun Xu et al. This is an open access article distributed under the Creative Commons Attribution License, which permits unrestricted use, distribution, and reproduction in any medium, provided the original work is properly cited.

\begin{abstract}
Threshold pressure gradient (TPG) and stress sensitivity which cause the nonlinear flow in low permeability reservoirs were carried out by experiments. Firstly, the investigation of existing conditions of TPG for oil flow in irreducible water saturation low-permeability reservoirs was conducted and discussed, using the cores from a real offshore oilfield in China. The existence of TPG was proven. The relationship between TPG and absolute permeability was obtained by laboratory tests. TPG increases with decreasing absolute permeability. Then, stress sensitivity experiment was carried out through depressurizing experiment and step-up pressure experiment. Permeability modulus which characterizes stress sensitivity increases with decreasing absolute permeability. Consequently, a horizontal well pressure transient analysis mathematical model considering threshold pressure gradient and stress sensitivity was established on the basis of mass and momentum conservation equations. The finite element method (FEM) was presented to solve the model. Influencing factors, such as TPG, permeability modulus, skin factor, wellbore storage, horizontal length, horizontal position, and boundary effect on pressure and pressure derivative curves, were also discussed. Results analysis demonstrates that the pressure transient curves are different from Darcy's model when considering the nonlinear flow characteristics. Both TPG and permeability modulus lead to more energy consumption and the reservoir pressure decreases more than Darcy's model.
\end{abstract}

\section{Introduction}

With the growing tension of oil and gas resources, low permeability reservoirs have become the most important source of oil exploration and development in China's petroleum industry. They are taking up nearly half reserves of oil and gas, respectively.

For the low permeability formation, fluid flow in reservoir has some special characteristics which can be summarized as follows: (1) flow departures from Darcy's law at low-velocity fluid flow. Many authors have noted the departures from Darcy's law in porous media through experiment methods [1-6] and they found that the flow curve is a combination of a straight line and a concave curve. Non-Darcy's flow exists in low permeability porous media in which the TPG always can be observed. Some scholars expounded the nonDarcy phenomenon and thought that it has significant effect on petroleum development. In 2004, Gavin [7] gave a detailed discussion on the non-Darcy phenomenon under low-velocity conditions in porous media. Basak [8] identified low-velocity fluid flow as "pre-Darcy flow," where the increase of fluid flow velocity can be greater than that proportional to the increase of fluid pressure gradient. For tight gas reservoir, the non-Darcy flow was also observed in a water-bearing reservoir and the TPG exists $[9,10]$. Currently, the non-Darcy flow has been discussed in many fields in petroleum including numerical simulation, enhanced oil recovery, productivity evaluation, and well test [11-14]. So it is significant to research on the non-Darcy phenomenon thoroughly.

(2) Stress sensitivity is obvious which cannot be ignored. Stress sensitivity phenomenon is common in many kinds of reservoirs, which is defined as reservoir rocks with fluidflow characteristics (permeability) that are highly sensitive to the effective stress changes and/or if they are of weak mechanical strength causing large rock deformation and are considered to be stress-sensitive [15-19]. For the low permeability formation, the deformational characteristics of rocks are always observed and have a great effect on well 
TABLE 1: Property of natural cores in displacement experiment.

\begin{tabular}{lccccc}
\hline Sample number & $\begin{array}{c}\text { Porosity } \\
(\%)\end{array}$ & $\begin{array}{c}\text { Length } \\
L(\mathrm{~cm})\end{array}$ & $\begin{array}{c}\text { Diameter } \\
D(\mathrm{~cm})\end{array}$ & $\begin{array}{c}\text { Area } \\
A\left(\mathrm{~cm}^{2}\right)\end{array}$ & $\begin{array}{c}\text { Permeability } \\
K\left(\times 10^{-3} \mu \mathrm{m}^{2}\right)\end{array}$ \\
\hline 1 & 17.7 & 3.118 & 2.548 & 5.098893 & 26.8 \\
2 & 16.8 & 6.642 & 2.538 & 5.058949 & 13.4 \\
3 & 15.3 & 2.568 & 2.544 & 5.082897 & 8.04 \\
4 & 17.0 & 4.772 & 2.544 & 5.082897 & 6.7 \\
5 & 15.5 & 4.254 & 2.566 & 5.171189 & 5.36 \\
6 & 15.8 & 5.864 & 2.538 & 5.058949 & 4.02 \\
\hline
\end{tabular}

TABLE 2: Property of natural cores in stress sensitivity experiment.

\begin{tabular}{lccccc}
\hline Sample number & $\begin{array}{c}\text { Porosity } \\
(\%)\end{array}$ & $\begin{array}{c}\text { Length } \\
L(\mathrm{~cm})\end{array}$ & $\begin{array}{c}\text { Diameter } \\
D(\mathrm{~cm})\end{array}$ & $\begin{array}{c}\text { Area } \\
\left(\mathrm{cm}^{2}\right)\end{array}$ & $\begin{array}{c}\text { Permeability } \\
K\left(\times 10^{-3} \mu \mathrm{m}^{2}\right)\end{array}$ \\
\hline 7 & 15.6 & 4.085 & 2.552 & 5.112473 & 2.218 \\
8 & 15.9 & 3.065 & 2.553 & 5.11648 & 4.097 \\
9 & 15.8 & 5.215 & 2.57 & 5.184847 & 4.666 \\
10 & 16.8 & 7.042 & 2.567 & 5.172749 & 8.670 \\
11 & 17.2 & 7.124 & 2.582 & 5.233378 & 16.200 \\
\hline
\end{tabular}

productivity [20, 21]. The study on stress sensitivity for low permeability formation is meaningful.

For the offshore low permeability oil field, the horizontal well is always used to achieve an efficient development. To obtain the formation parameters, pressure transient analysis is often used. Many scholars had done study on interpretations of formation parameters using pressure data [22-27]. But for low permeability reservoirs, this work has not been done by considering threshold pressure gradient and stress sensitivity which cause the nonlinear flow.

In this paper, firstly, threshold pressure gradient and stress sensitivity experiments in low permeability oil reservoirs were made and discussed using the cores from a real offshore oilfield in China. Then, the pressure transient analysis mathematical model was derived for the horizontal well. FEM was proposed to solve the model. The sensitivity of the type curves and derivative type curves on monitoring TPG, permeability modulus, well location, well length, wellbore storage, and skin factor was analyzed finally.

\section{Experimental Measurement and Analysis}

2.1. TPG Experiment. Six natural cores were taken from a low permeability reservoir in the a real offshore oilfield in China, with the diameter of $2.5 \mathrm{~cm}$, length range of $2.568 \mathrm{~cm}-6.642 \mathrm{~cm}$, permeability range of $(4.02-26.8) \times$ $10^{-3} \mu \mathrm{m}^{2}$, and porosity range of $15.3-17.7 \%$ (shown in Table 1 ). The simulated oil was a mixture of degassing crude oil and kerosene, with viscosity of $1.332 \mathrm{mPa} \cdot \mathrm{s}$ and density of $0.84 \mathrm{~g} / \mathrm{mL}$. The salinity of formation water was $7.0 \mathrm{mg} / \mathrm{mL}$ $\left(\mathrm{NaCl}: \mathrm{CaCl}_{2}: \mathrm{MgCl}_{2} \cdot 6 \mathrm{H}_{2} \mathrm{O}=7: 0.6: 0.4\right)$ and the viscosity is $1.15 \mathrm{mPa} \cdot \mathrm{s}$.

In order to investigate TPG in low permeability cores, the experimental equipment designed by Wang et al. [3] was used, which includes five parts: power system, buffer system, core holder system, confining pressure system, and the measurement system. In Wang' experiment, water was the displaced fluid; in our experiment, the experiment procedure was adjusted in which the displaced fluid was simulated oil and the cores were in irreducible water saturation state (Figure 1).

During the experiments, the following data needed to be recorded: inlet pressure of the core holder, fluid volume, and residual pressure. After one displacement, the curve of velocity-pressure gradient was plotted. By epitaxial method, we can get the intersection between straight line and pressure axis, which is defined as pseudothreshold pressure gradient (TPG).

2.2. Stress Sensitivity Experiment. Five natural cores were taken from a low permeability reservoir in the South China sea oilfield, with the diameter of $2.5 \mathrm{~cm}$, length range of $3.065 \mathrm{~cm}-7.124 \mathrm{~cm}$, permeability range of $(2.218-16.200) \times$ $10^{-3} \mu \mathrm{m}^{2}$, and porosity range of $15.6-17.2 \%$ (shown in Table 2 ). The simulated oil was a mixture of degassing crude oil and kerosene, with viscosity of $1.332 \mathrm{mPa} \cdot \mathrm{s}$ and density of $0.84 \mathrm{~g} / \mathrm{mL}$. The salinity of formation water is $7.0 \mathrm{mg} / \mathrm{mL}$ $\left(\mathrm{NaCl}: \mathrm{CaCl}_{2}: \mathrm{MgCl}_{2} \cdot 6 \mathrm{H}_{2} \mathrm{O}=7: 0.6: 0.4\right)$ and the viscosity was $1.15 \mathrm{mPa} \cdot \mathrm{s}$. The experimental equipment in Section 2.1 was used.

The overburden pressure of the study formation is about $22 \mathrm{MPa}$, so the confining pressure was set as $22 \mathrm{MPa}$. Two kinds of experiments were conducted-depressurizing experiment and step-up pressure experiment. During the experiment, the confining pressure is maintained and inlet/outlet pressure difference is kept as $0.5 \mathrm{MPa}$. The back-pressure and inlet pressure were adjusted to a given value. The flow rate, inlet and outlet pressure, and pressure differential were recorded, and the core permeability was calculated at a certain pressure when the flow was in steady state. Inlet/outlet pressures are then gradually decreased (depressurizing experiment) or increased (step-up pressure experiment) and the 


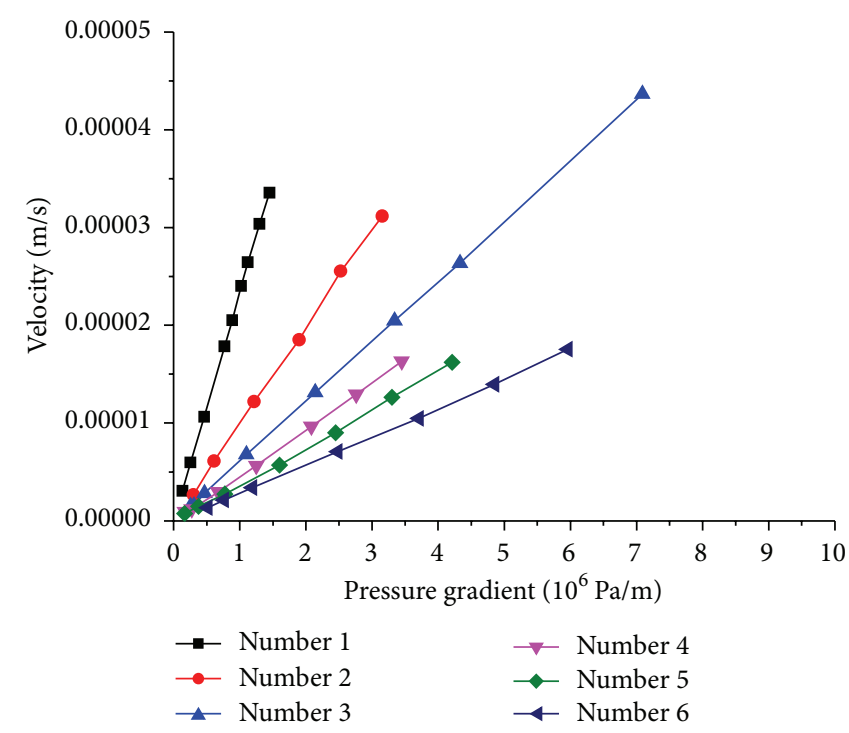

FIgURE 1: Experiment results of simulated oil displacement.

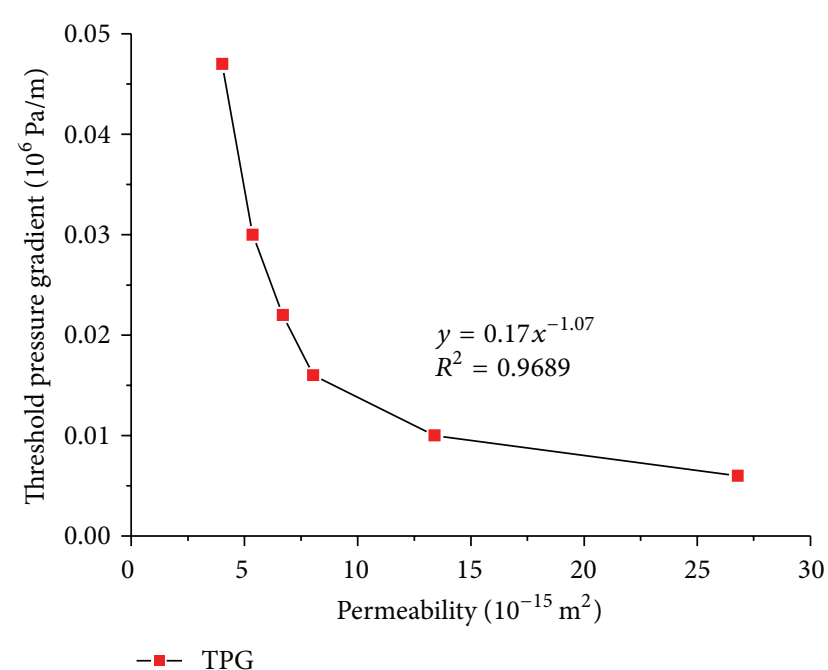

FIGURE 2: Relationship between TPG and permeability.

displacement experiment was repeated. The core permeability was calculated at each pressure.

2.3. Analysis of Nonlinear Experiment. The TPG exists in low permeability reservoirs. From Figure 2, we can see that TPG versus permeability presents power function and the TPG will decrease.

Wang et al. [20] described the stress sensitivity with the permeability modulus $\boldsymbol{\alpha}$ which is defined as follows:

$$
\alpha=\frac{1}{K} \frac{d K}{d p} .
$$

So the permeability can be modified as

$$
K=K_{i} e^{-\alpha\left(p_{i}-p\right)} .
$$

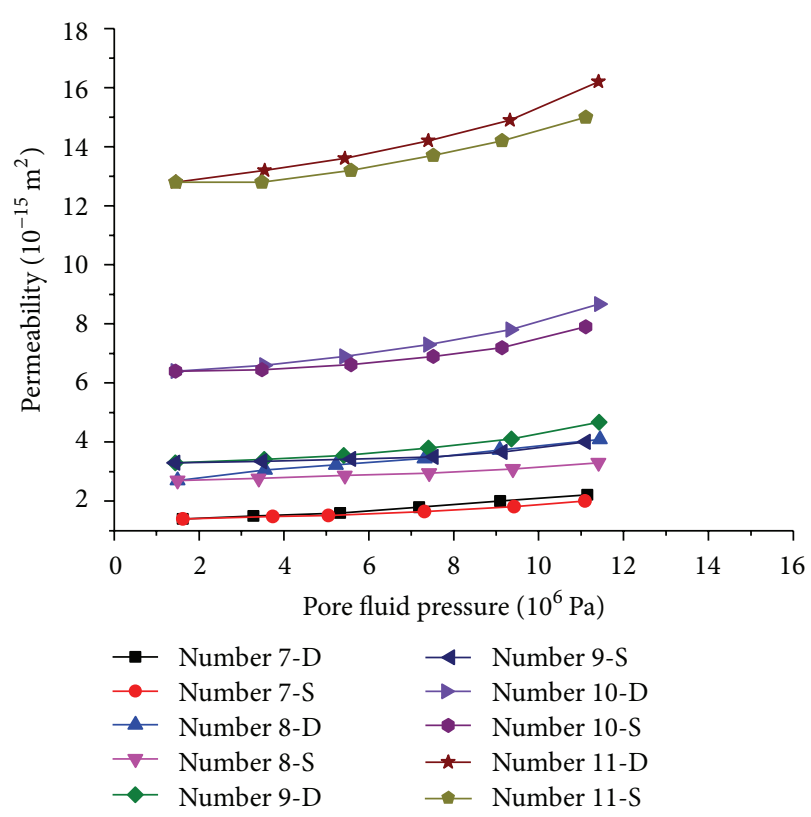

FIGURE 3: Relationship between pore fluid pressure and permeability.

From Figure 3, we can see that the stress sensitivity exists widely in low permeability reservoirs for offshore oilfield cores both in depressurizing experiment and step-up pressure experiment. The dimensionless permeability (defined as $\left.K / K_{\max }\right)$ and permeability modulus were calculated in the experiment as shown in Figure 4 and Table 3. For the 5 cores, as the permeability increases, the permeability modulus increases and the permeability modulus in depressurizing experiment is larger than step-up pressure experiment.

It can be seen, in the low permeability reservoir, that the TPG and stress sensitivity always exist. The TPG and 


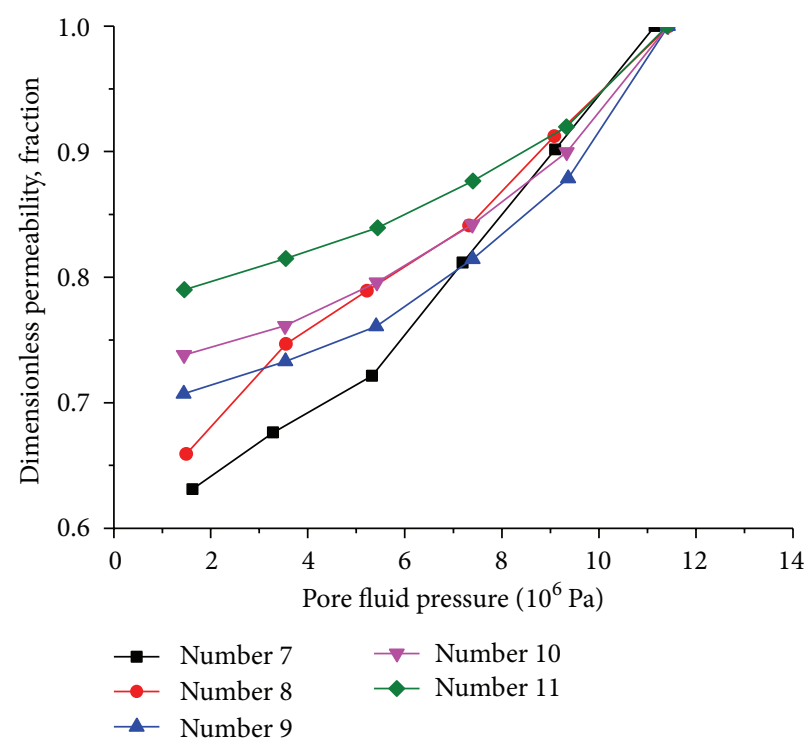

(a) Depressurizing experiment

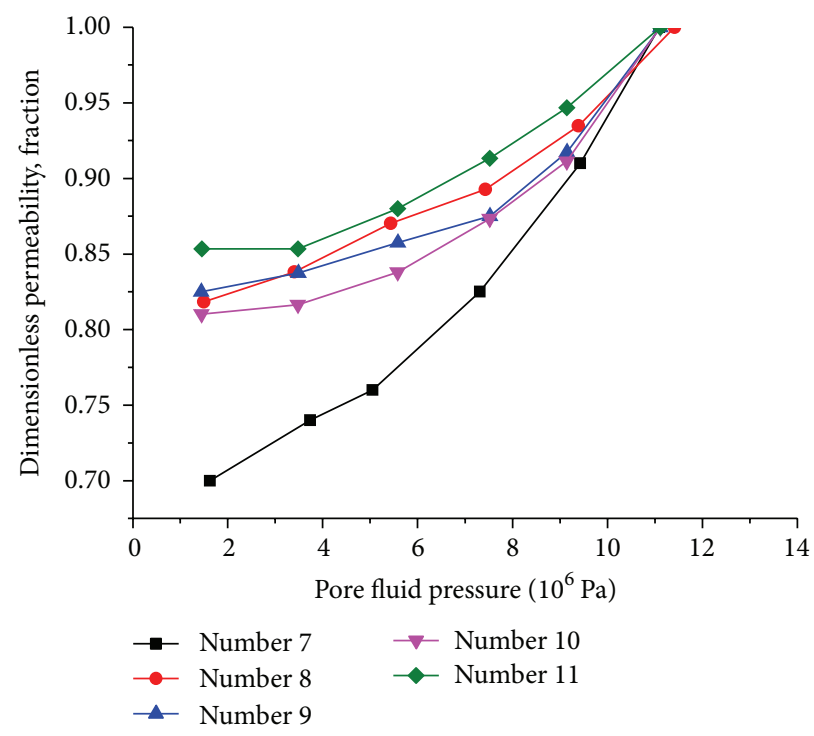

(b) Step-up pressure experiment

FIGURE 4: Relationship between pore fluid pressure and dimensionless permeability.

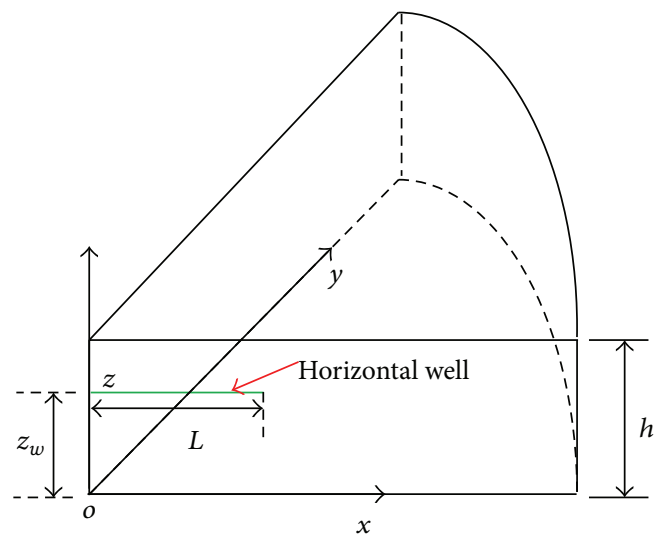

FIGURE 5: Schematic diagram of a horizontal well in a low permeability reservoir.

TABLE 3: Permeability modulus for different core samples.

\begin{tabular}{lcc}
\hline Sample & $\begin{array}{c}\text { Permeability modulus } \\
\text { (depressurizing)/(MPa }\end{array}$ & $\begin{array}{c}\text { Permeability } \\
\text { modulus (step-up } \\
\text { pressure)/MPa }\end{array}$ \\
\hline 7 & 0.049 & 0.037 \\
8 & 0.043 & 0.020 \\
9 & 0.034 & 0.019 \\
10 & 0.030 & 0.021 \\
11 & 0.023 & 0.014 \\
\hline
\end{tabular}

permeability modulus become larger in absolute value when the core has a smaller permeability.

\section{A Horizontal Well in an Anisotropic Low Permeability Reservoir}

The nonlinear experiment which contains TPG experiment and stress sensitivity experiment indicates that, in low permeability reservoir, TPG and stress sensitivity cannot be ignored, so when conducting pressure transient analysis for wells, they should be considered. In this section, the horizontal well pressure transient analysis model was established and the solution method was discussed considering nonlinear flow characteristics.

3.1. Mathematical Model. Figure 5 is a schematic diagram of the horizontal well in a reservoir. The $x-y$-axes are in the horizontal directions and the $z$-axes in the vertical direction. The origin is at the bottom of the reservoir. Some assumptions are made as follows.

(1) The outer boundary of a circular reservoir is closed or with constant pressure; reservoir radius is $r_{e}$.

(2) The reservoir is horizontal with uniform thickness of $h$ and original pressure $p_{i}$.

(3) Reservoir permeability anisotropy is considered, with horizontal permeability $k_{h}$ and vertical permeability $k_{v}$.

(4) The well is located in the $x o z$ plane with perforated length of $2 L$; this well is produced at constant production rate of $Q$.

(5) The reservoir fluid is slightly compressible, with compressibility $C_{t}$ and viscosity of crude oil $\mu$.

(6) The reservoir media is deformational, with permeability modulus $\alpha$ and TPG $\lambda$. 
(7) The influence of gravity and capillary forces can be ignored.

(8) Wellbore storage effect and formation damage are taken into account.

3.2. Mathematical Model. The mathematical model in low permeability reservoir is

$$
\begin{gathered}
\frac{\partial}{\partial x}\left(\frac{K_{x}}{\mu} \delta_{K x} \frac{\partial p}{\partial x}\right)+\frac{\partial}{\partial y}\left(\frac{K_{y}}{\mu} \delta_{K y} \frac{\partial p}{\partial y}\right) \\
+\frac{\partial}{\partial z}\left(\frac{K_{z}}{\mu} \delta_{K z} \frac{\partial p}{\partial z}\right)=\phi C_{t} \frac{\partial p}{\partial t}+q .
\end{gathered}
$$

Assuming $K_{x}=K_{y}=K_{h}, K_{z}=K_{v}$ and ignoring source and sink term, the equation will be changed to

$$
\begin{gathered}
\frac{K_{h i}}{\mu}\left[\frac{\partial}{\partial x}\left(e^{-\alpha\left(p_{i}-p\right)} \delta_{K x} \frac{\partial p}{\partial x}\right)+\frac{\partial}{\partial y}\left(e^{-\alpha\left(p_{i}-p\right)} \delta_{K y} \frac{\partial p}{\partial y}\right)\right. \\
\left.+\frac{\partial}{\partial z}\left(e^{-\alpha\left(p_{i}-p\right)} \delta_{K z} \beta \frac{\partial p}{\partial z}\right)\right]=\phi C_{t} \frac{\partial p}{\partial t} .
\end{gathered}
$$

Initial condition is

$$
p(x, y, z, t=0)=p_{i} .
$$

Closed outer boundary is

$$
\left.\frac{\partial p}{\partial r}\right|_{r=r_{e}}=\left.\frac{\partial p}{\partial z}\right|_{z=z_{e}}=0
$$

Constant-pressure outer boundary is

$$
p\left(r=r_{e}\right)=p\left(z=z_{e}\right)=p_{i} .
$$

Some dimensionless terms are defined as Appendix A shows. So the dimensionless mathematical model will be

$$
\begin{gathered}
\frac{\partial}{\partial x_{D}}\left(e^{-\alpha_{D} p_{D}} \delta_{K D x} \frac{\partial p_{D}}{\partial x_{D}}\right) \\
+\frac{\partial}{\partial y_{D}}\left(e^{-\alpha_{D} p_{D}} \delta_{K D y} \frac{\partial p_{D}}{\partial y_{D}}\right) \\
+\frac{\partial}{\partial z_{D}}\left(e^{-\alpha_{D} p_{D}} \delta_{K D z} L_{D}^{2} \frac{\partial p_{D}}{\partial z_{D}}\right) \\
=\left(h_{D} L_{D}\right)^{2} \frac{\partial p_{D}}{\partial t_{D}}, \quad=0, \\
p_{D}\left(x_{D}, y_{D}, z_{D}, t_{D}=0\right)=0, \\
\left.\frac{\partial p_{D}}{\partial r_{D}}\right|_{r_{D}=r_{e D}}=\left.\frac{\partial p_{D}}{\partial z_{D}}\right|_{z_{D}=0,1}=0, \\
p_{D}\left(r_{D}=r_{e D}\right)=p_{f D}\left(z_{D}=0,1\right)=0 .
\end{gathered}
$$

For this model, the inner boundary condition is constant rate production. The equation of inner boundary condition is shown in Appendix B.2.

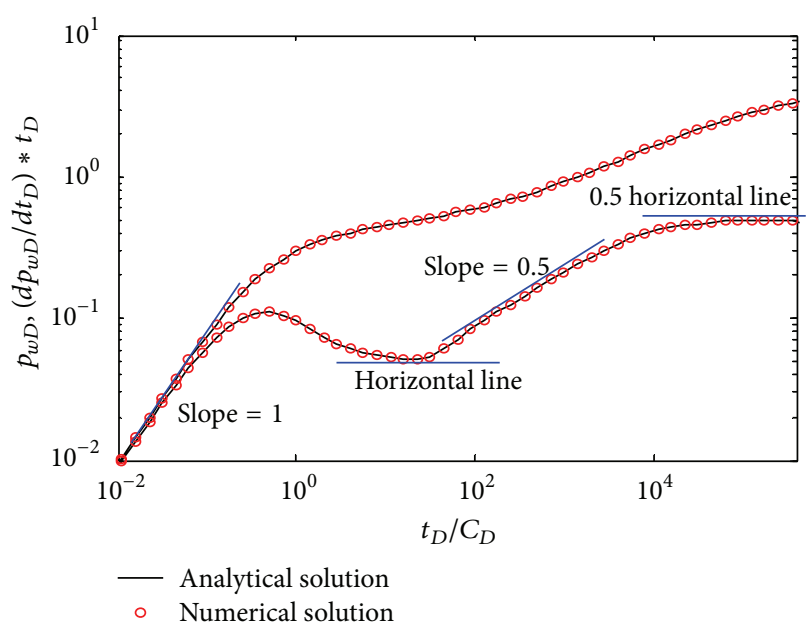

Figure 6: Comparison of analytical solution and numerical solution $\left(C_{D}=100 ; S=0 ; L_{D}=5 ; h_{D}=200 ; \alpha_{D}=0 ; \lambda_{D}=0\right)$.

\section{Computational Issues}

The FEM is used to solve this model. The detailed solution procedure is shown in Appendix B. The GMRES method was used to solve the equation system [28].

\section{Results and Discussions}

5.1. Pressure Transient Behavior. To verify the accuracy of the model, comparisons are made with the solution by $\mathrm{Li}$ et al. [29]. The comparison was made without considering the TPG and permeability modulus. As shown in Figure 6, the type curves and derivative type curves from our model are in good agreement with those from Li et al. [29]. From Figure 6 we can see that considering the TPG and stress sensitivity four stages are observed: (1) early pure wellbore storage stage which is characterized by a 1 slope in pressure derivative curve; (2) early vertical radial flow stage which is characterized by a horizontal line in pressure derivative curve; (3) linear flow stage which is characterized by a $1 / 2$ slope in pressure derivative curve; (4) late radial flow stage which is characterized by a 0.5 horizontal line in pressure derivative curve.

From Figure 7, we can see that the pressure and pressure derivative curves when considering stress sensitivity and TPG are different from those based on Darcy's model. The effects of stress sensitivity and TPG cause the pressure and pressure derivative curves to shift upwards in the late stage, resulting in the disappearance of pressure derivative horizon with the value of 0.5 in radial flow stage. Because of the upward of the curves, late radial flow stage tends to be like linear flow. The reason is that in the formation there is additional pressure loss when considering TPG and stress sensitivity. The flow equation never obeys Darcy's model.

Compared with the stress sensitivity, TPG can cause more deviation to the pressure and pressure derivative curves. This is because that horizontal well has a large contact with the reservoir, pressure gradient near the wellbore is not as large 


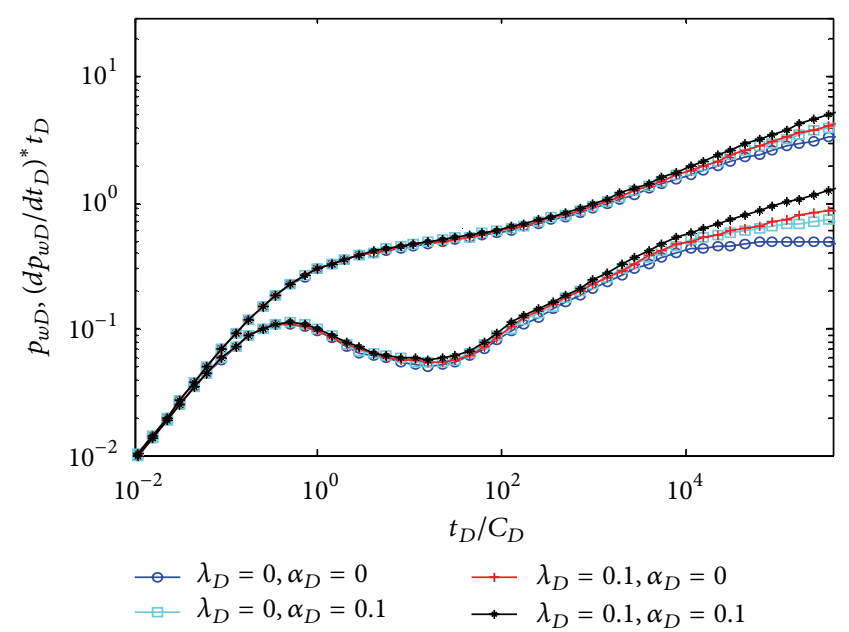

FIGURE 7: Comparison of dimensionless type curves with considering TPG and stress sensitivity $\left(C_{D}=100 ; S=0 ; L_{D}=5 ; h_{D}=200\right)$.

as in a vertical well but is the main section of TPG effect, and thus the effect of stress sensitivity is not as obvious as TPG. When considering the two factors together, the degree of the upward for the curve is the supposition of the two factors to be considered separately.

5.2. Sensitivity Analysis. In this section, the sensitivity analysis was obtained which includes the TPG, permeability modulus, skin factor, wellbore storage, horizontal length, horizontal position, and boundary effect.

For each sensitivity parameter, the pressure and pressure derivative curves were presented. In each figure, the dimensionless parameters were given based on the definition in Appendix A.

(1) Effect of $C_{D}$. Figures 8 and 9 show the effect of wellbore storage coefficient on well test curves. The basic parameters are $h=9 \mathrm{~m} ; r_{w}=0.1 \mathrm{~m} ; L=100 \mathrm{~m} ; K_{h}=9 \times 10^{-15} \mathrm{~m}^{2} ; K_{v}$ $=1.8 \times 10^{-15} \mathrm{~m}^{2} ; \mu=1 \times 0.001 \mathrm{~Pa} \cdot \mathrm{s} ; S=0 ; C=0.016 \times$ $10^{-6} \mathrm{~m}^{3} / \mathrm{Pa}, 0.032 \times 10^{-6} \mathrm{~m}^{3} / \mathrm{Pa}, 0.16 \times 10^{-6} \mathrm{~m}^{3} / \mathrm{Pa} ; \varphi=0.25$; $c_{t}=0.0022 \times 10^{-6} \mathrm{~Pa}^{-1} ; \alpha=0.049 \times 10^{-6} \mathrm{~Pa}^{-1} ; \lambda=0.002 \times$ $10^{6} \mathrm{~Pa} / \mathrm{m}$; and $Z_{w}=4.5 \mathrm{~m}$. Large wellbore storage coefficient causes the pressure curve to shift upward, and the larger the wellbore storage coefficient is, the higher the "hump" of the pressure derivative curve is and the earlier linear flow occurs. When the wellbore storage coefficient is large enough, the early radial flow stage will be concealed by linear flow. When the horizontal axis is $t_{D}$, it can be seen that the variation of wellbore storage coefficient causes different duration time of the wellbore storage stage, resulting in horizontal shift of the well test curve. The pressure and pressure derivate curves coincide together at later time.

(2) Effect of $S$. Figure 10 shows the effect of the skin factor on well test curves. The basic parameters are $h=9 \mathrm{~m} ; r_{w}=$ $0.1 \mathrm{~m} ; L=100 \mathrm{~m} ; K_{h}=9 \times 10^{-15} \mathrm{~m}^{2} ; K_{v}=1.8 \times 10^{-15} \mathrm{~m}^{2}$; $\mu=1 \times 0.001 \mathrm{~Pa} \cdot \mathrm{s} ; S=1,5,10 ; C=0.032 \times 10^{-6} \mathrm{~m}^{3} / \mathrm{Pa}$; $\varphi=0.25 ; c_{t}=0.0022 \times 10^{-6} \mathrm{~Pa}^{-1} ; \alpha=0.049 \times 10^{-6} \mathrm{~Pa}^{-1} ;$

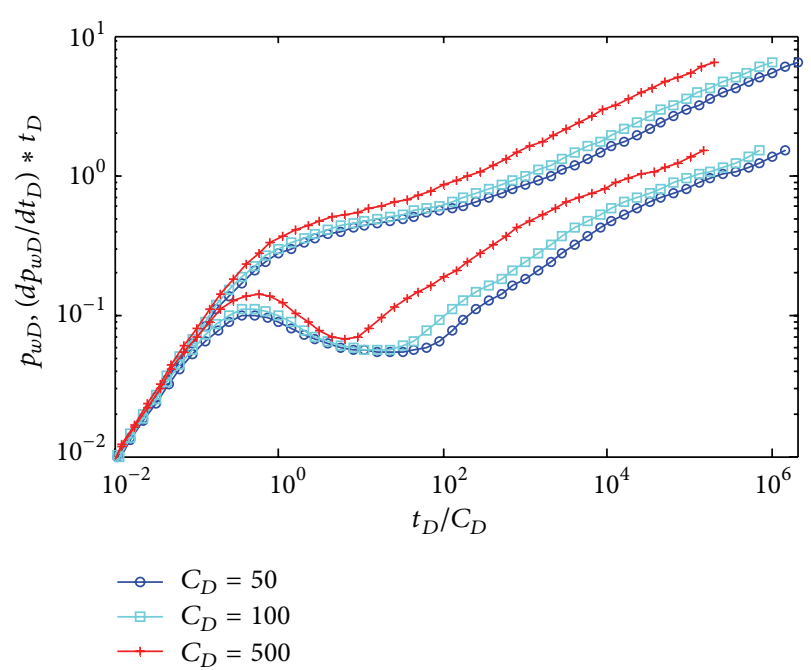

FIGURE 8: Comparison of dimensionless type curves with different dimensionless wellbore storage coefficients $\left(S=0 ; L_{D}=5 ; h_{D}=200\right.$; $\alpha_{D}=0.1 ; \lambda_{D}=0.1$.

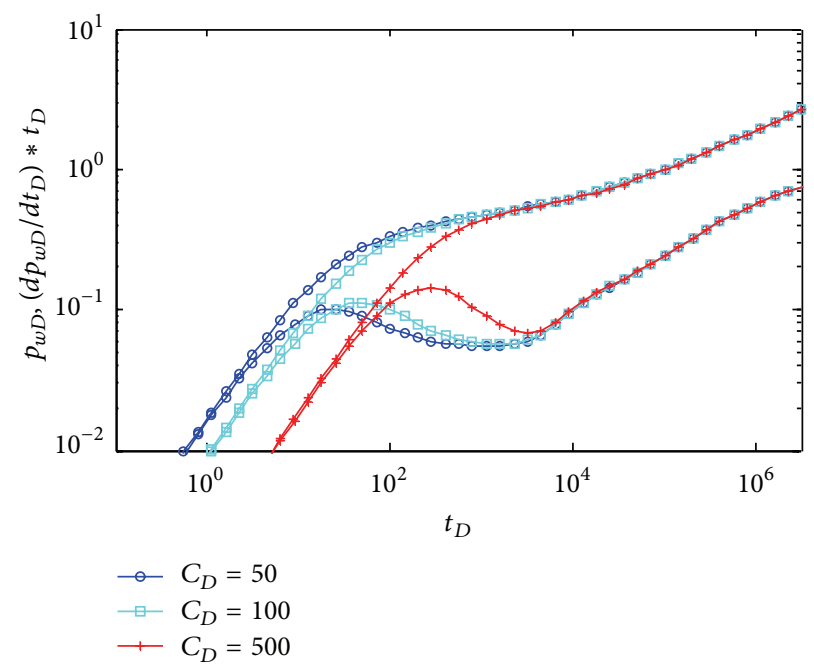

FIGURE 9: Comparison of dimensionless type curves with different dimensionless wellbore storage coefficients $\left(S=0 ; L_{D}=5 ; h_{D}=200\right.$; $\alpha_{D}=0.1 ; \lambda_{D}=0.1$.

$\lambda=0.002 \times 10^{6} \mathrm{~Pa} / \mathrm{m}$; and $Z_{w}=4.5 \mathrm{~m}$. The larger skin factor represents heavier pollution and greater additional pressure drop; it also causes higher "hump" on well test curve. Large skin factor may shorten the early radial flow segment or even make it disappear.

(3) Effect of $\alpha_{D}$. Figure 11 shows the effect of the permeability modulus on well test curves. The basic parameters are $h=$ $9 \mathrm{~m} ; r_{w}=0.1 \mathrm{~m} ; L=200 \mathrm{~m} ; K_{h}=9 \times 10^{-15} \mathrm{~m}^{2} ; K_{v}=1.8 \times$ $10^{-15} \mathrm{~m}^{2} ; \mu=1 \times 0.001 \mathrm{~Pa} \cdot \mathrm{s} ; S=0 ; C=0.032 \times 10^{-6} \mathrm{~m}^{3} / \mathrm{Pa} ; \varphi=$ $0.25 ; c_{t}=0.0022 \times 10^{-6} \mathrm{~Pa}^{-1} ; \alpha=0,0.023 \times 10^{-6} \mathrm{~Pa}^{-1}, 0.049 \times$ $10^{-6} \mathrm{~Pa}^{-1} ; \lambda=0.003 \times 10^{6} \mathrm{~Pa} / \mathrm{m}$; and $Z_{w}=4.5 \mathrm{~m}$. According to the core experiment, the largest permeability modulus in absolute value is $0.049 \times 10^{-6} \mathrm{~Pa}^{-1}$. So we set the largest 


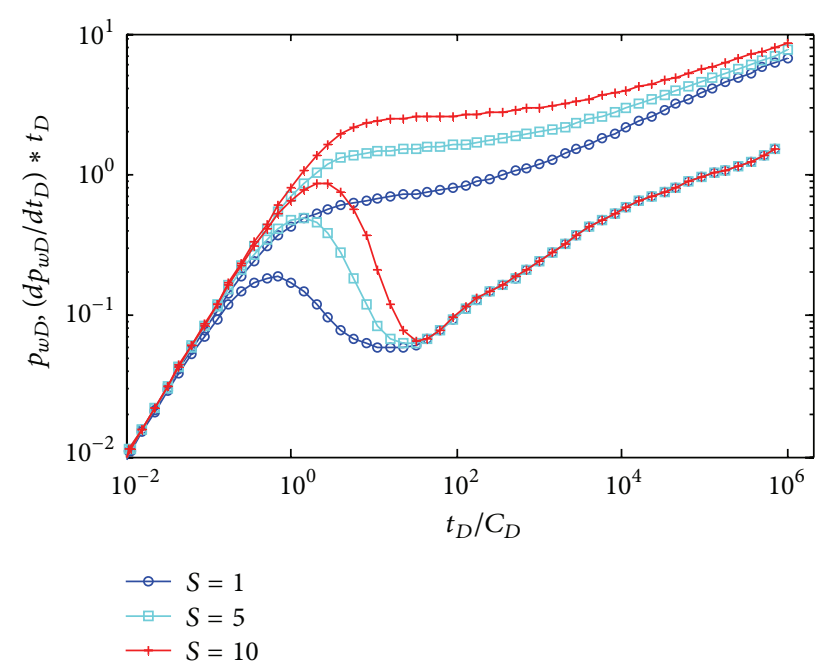

FIGURE 10: Comparison of dimensionless type curves with different skin factors $\left(L_{D}=5 ; h_{D}=200 ; \alpha_{D}=0.1 ; \lambda_{D}=0.1\right)$.

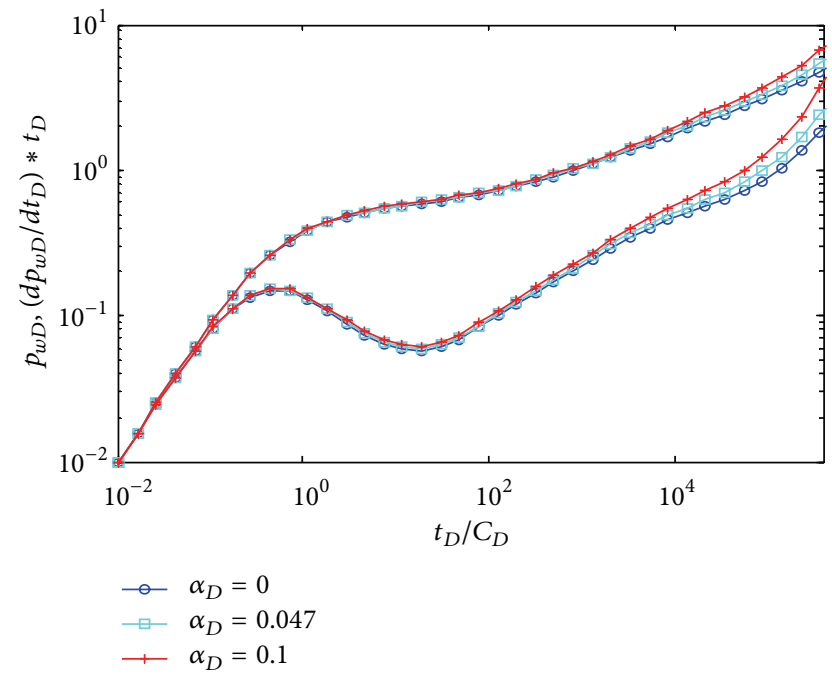

Figure 11: Comparison of dimensionless type curves with different permeability moduli $\left(C_{D}=100 ; S=0 ; L_{D}=5 ; h_{D}=200 ; \lambda_{D}=0.15\right)$.

permeability modulus equal to the $0.049 \times 10^{-6} \mathrm{~Pa}^{-1}$. Large permeability modulus makes the reservoir more sensitive to the stress, causing the pressure and pressure derivate curves to increase seriously. Effect of stress sensitivity on the curve mainly concentrates on the stages after the linear flow.

(4) Effect of $\lambda_{D}$. Figure 12 shows the effect of TPG on horizontal well test curves. The basic parameters are $h=9 \mathrm{~m}$; $r_{w}=0.1 \mathrm{~m} ; L=100 \mathrm{~m} ; K_{h}=9 \times 10^{-15} \mathrm{~m}^{2} ; K_{y}=1.8 \times 10^{-15} \mathrm{~m}^{2}$; $\mu=1 \times 0.001 \mathrm{~Pa} \cdot \mathrm{s} ; S=0 ; C=0.032 \times 10^{-6} \mathrm{~m}^{3} / \mathrm{Pa} ; \varphi=0.25$; $c_{t}=0.0022 \times 10^{-6} \mathrm{~Pa}^{-1} ; \alpha=0.0245 \times 10^{-6} \mathrm{~Pa}^{-1} ; \lambda=0 \times$ $10^{6} \mathrm{~Pa} / \mathrm{m}, 0.006 \times 10^{6} \mathrm{~Pa} / \mathrm{m}, 0.047 \times 10^{6} \mathrm{~Pa} / \mathrm{m}$; and $Z_{w}=4.5 \mathrm{~m}$. According to the core experiment, the largest permeability modulus in absolute value is $0.047 \times 10^{6} \mathrm{~Pa} / \mathrm{m}$. So we set the largest TPG equal to the $0.047 \times 10^{6} \mathrm{~Pa} / \mathrm{m}$. The large TPG represents strong non-Darcy flow, resulting in large

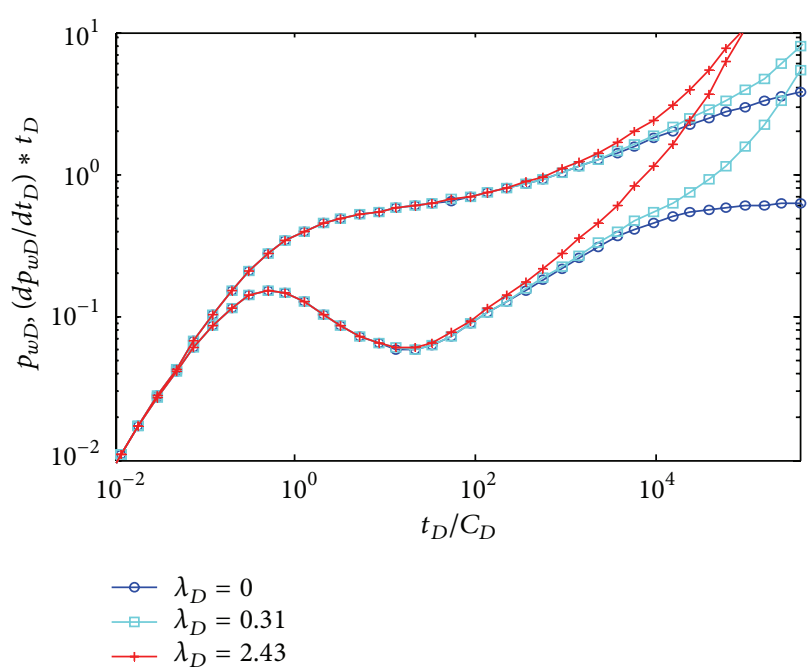

FIGURE 12: Comparison of dimensionless type curves with different TPGs $\left(C_{D}=100 ; S=0 ; L_{D}=5 ; h_{D}=200 ; \alpha_{D}=0.05\right)$.

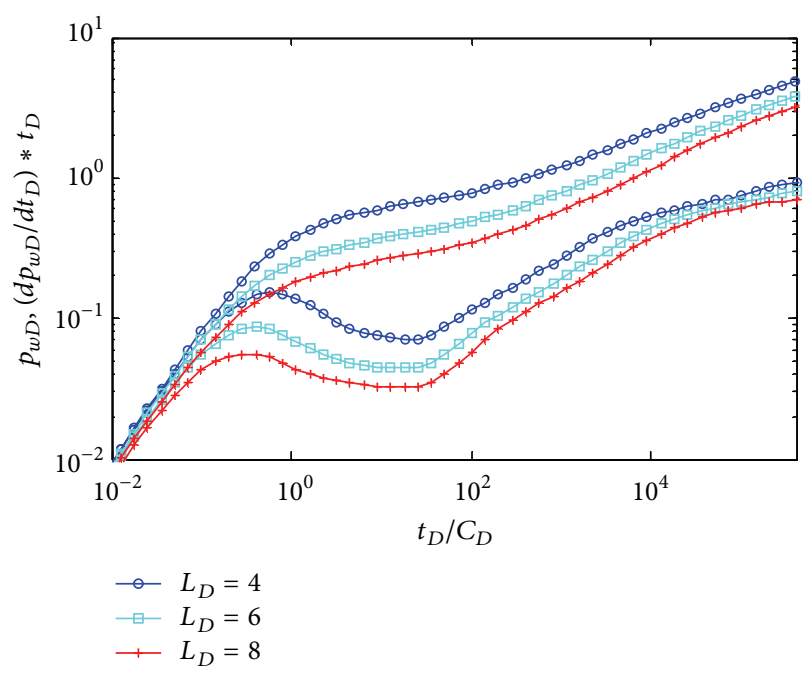

FIgURE 13: Comparison of dimensionless type curves with different horizontal well lengths $\left(C_{D}=100 ; S=0 ; h_{D}=200 ; \alpha_{D}=0.05 ; \lambda_{D}=\right.$ 0.05).

flow resistance. The larger the TPG is, the more upturned the pressure and pressure derivate curves are. The amount of upturning grows with time. The 0.5 value of pressure derivative curve disappears and boundary between the linear flow and late radial flow is not obvious.

(5) Effect of $L_{D}$. Figure 13 shows the effect of the horizontal well length. The basic parameters are $h=9 \mathrm{~m} ; r_{w}=0.1 \mathrm{~m} ; L$ $=80 \mathrm{~m}, 120 \mathrm{~m}, 160 \mathrm{~m} ; K_{h}=9 \times 10^{-15} \mathrm{~m}^{2} ; K_{v}=1.8 \times 10^{-15} \mathrm{~m}^{2}$; $\mu=1 \times 0.001 \mathrm{~Pa} \cdot \mathrm{s} ; S=0 ; C=0.032 \times 10^{-6} \mathrm{~m}^{3} / \mathrm{Pa} ; \varphi=0.25$; $c_{t}=0.0022 \times 10^{-6} \mathrm{~Pa}^{-1} ; \alpha=0.0245 \times 10^{-6} \mathrm{~Pa}^{-1} ; \lambda=0.001 \times$ $10^{6} \mathrm{~Pa} / \mathrm{m}$; and $Z_{w}=4.5 \mathrm{~m}$. It can be seen from the figure that the longer the horizontal well is, the lower the pressure and pressure derivate curves are and the more obvious the early radius flow is. Considering the effect of stress sensitivity and 


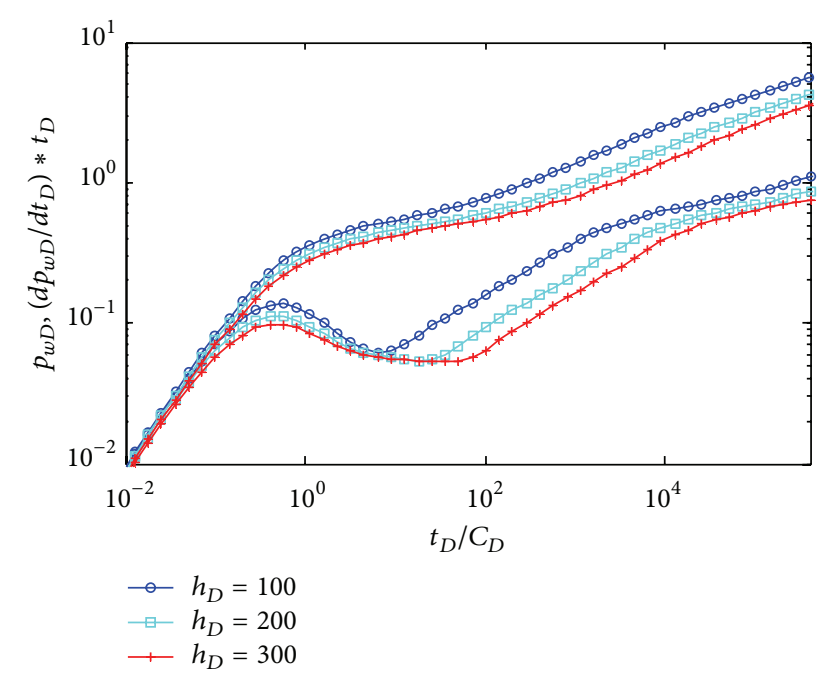

FIGURE 14: Comparison of dimensionless type curves with different reservoir thicknesses $\left(C_{D}=100 ; S=0 ; L_{D}=5 ; \alpha_{D}=0.05 ; \lambda_{D}=0.05\right)$.

nonlinear flow, the well test curves of different horizontal well lengths distributed parallel instead of coinciding together.

(6) Effect of $h_{D}$. Figure 14 shows the effect of reservoir thickness on well test curves. The basic parameters are $h=$ $4.5 \mathrm{~m}, 9 \mathrm{~m}, 13.5 \mathrm{~m} ; r_{w}=0.1 \mathrm{~m} ; L=100 \mathrm{~m} ; K_{h}=9 \times 10^{-15} \mathrm{~m}^{2}$; $K_{v}=1.8 \times 10^{-15} \mathrm{~m}^{2} ; \mu=1 \times 0.001 \mathrm{~Pa} \cdot \mathrm{s} ; S=0 ; C=0.032 \times$ $10^{-6} \mathrm{~m}^{3} / \mathrm{Pa} ; \varphi=0.25 ; c_{t}=0.0022 \times 10^{-6} \mathrm{~Pa}^{-1} ; \alpha=0.0245 \times$ $10^{-6} \mathrm{~Pa}^{-1}$; and $\lambda=0.001 \times 10^{6} \mathrm{~Pa} / \mathrm{m}$. We set $Z_{w}$ equal to $2.25 \mathrm{~m}$, $4.5 \mathrm{~m}$, and $6.75 \mathrm{~m}$, respectively, which makes the horizontal well locates in the center in vertical direction. It can be seen that the thicker the reservoir is, the longer the early radial flow stage is. When the reservoir thickness is very small, early radial flow will be concealed by the effects of wellbore storage.

For traditional horizontal well test, with the increase of reservoir thickness, the duration of early vertical radial flow lasts longer, and early radial flow stage (the slope of pressure and pressure derivative curves are 0.5) shifts backward. In the late radial flow period, the pressure derivative curves of different reservoir thickness coincide together to a horizontal line of 0.5 ; that is, the speed of pressure drop tends to be uniform.

After the introduction of permeability modulus and TPG, the duration of early vertical radial flow lasts longer with increasing reservoir thickness, and the effect of stress sensitivity and pseudolinear flow weakens, resulting in overall decrease of pure wellbore storage stage and backwardness of pressure and pressure derivative curves in linear flow. In the late radial flow period, pressure derivative curve is not a straight line at 0.5 ; the pressure and pressure derivative curves under different reservoir thicknesses upturn parallely.

(7) Effect of $z_{w D}$. Figure 15 shows the effect of the horizontal well position on the well test curve. The basic parameters are $h=9 \mathrm{~m} ; r_{w}=0.1 \mathrm{~m} ; L=100 \mathrm{~m} ; K_{h}=9 \times 10^{-15} \mathrm{~m}^{2} ; K_{v}=1.8 \times$ $10^{-15} \mathrm{~m}^{2} ; \mu=1 \times 0.001 \mathrm{~Pa} \cdot \mathrm{s} ; S=0,5,10 ; C=0.032 \times 10^{-6} \mathrm{~m}^{3} / \mathrm{Pa}$; $\varphi=0.25 ; c_{t}=0.0022 \times 10^{-6} \mathrm{~Pa}^{-1} ; \alpha=0.0245 \times 10^{-6} \mathrm{~Pa}^{-1} ;$

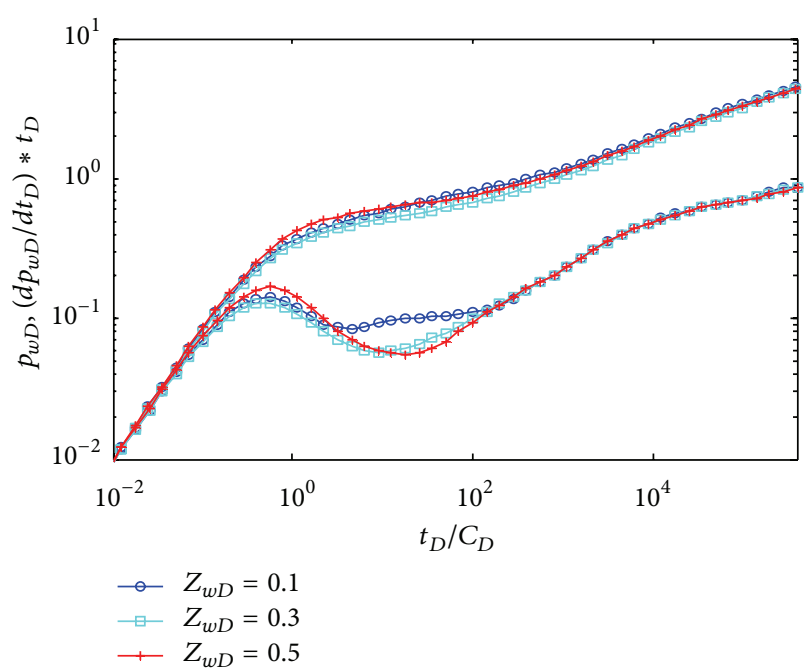

FIGURE 15: Comparison of dimensionless type curves with different horizontal well positions $\left(C_{D}=100 ; S=0 ; L_{D}=5 ; h_{D}=200 ; \alpha_{D}=\right.$ $\left.0.05 ; \lambda_{D}=0.05\right)$.

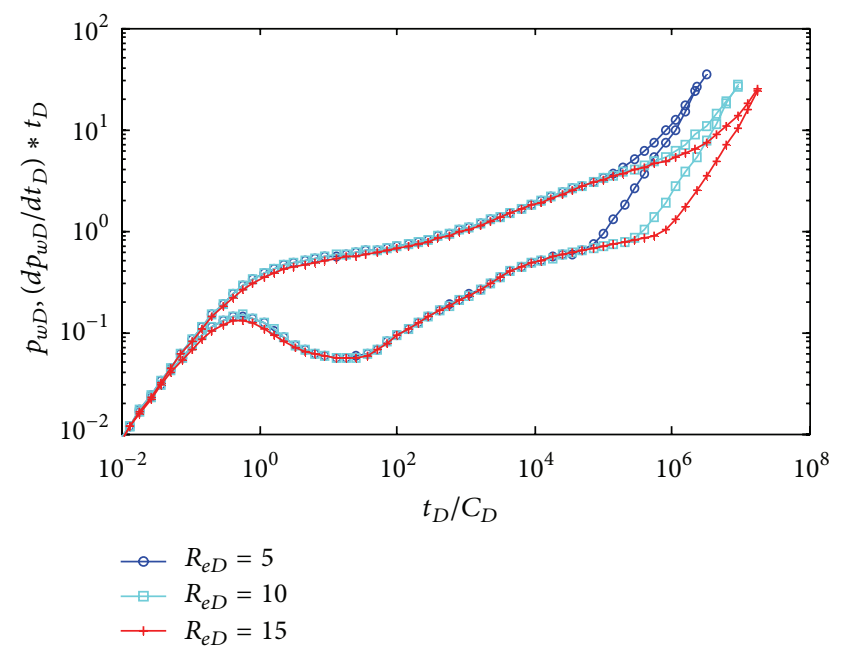

FIGURE 16: Comparison of dimensionless type curves with different closed outer boundaries $\left(C_{D}=100 ; S=0 ; L_{D}=5 ; h_{D}=200 ; \alpha_{D}=\right.$ $\left.0.05 ; \lambda_{D}=0.05\right)$.

$\lambda=0.001 \times 10^{6} \mathrm{~Pa} / \mathrm{m}$; and $Z_{w}=0.9 \mathrm{~m}, 2.7 \mathrm{~m}, 4.5 \mathrm{~m}$. It can be seen that when other parameters are kept constant, the closer to $0.5 z_{w D}$ is, that is, horizontal well is closer to the middle of the reservoir, the longer early radical flow lasts. Horizontal well position does not affect the wellbore storage segment, the linear flow, and late-linear flow segment.

(8) Effect of Outer Boundary. Figures 16 and 17 show boundary effect. The basic parameters are $h=9 \mathrm{~m} ; r_{w}=0.1 \mathrm{~m} ; L=$ $100 \mathrm{~m} ; K_{h}=9 \times 10^{-15} \mathrm{~m}^{2} ; K_{v}=1.8 \times 10^{-15} \mathrm{~m}^{2} ; \mu=1 \times$ $0.001 \mathrm{~Pa} \cdot \mathrm{s} ; \mathrm{S}=0 ; C=0.032 \times 10^{-6} \mathrm{~m}^{3} / \mathrm{Pa} ; \varphi=0.25 ; c_{t}=$ $0.0022 \times 10^{-6} \mathrm{~Pa}^{-1} ; \alpha=0.0245 \times 10^{-6} \mathrm{~Pa}^{-1} ; \lambda=0.001 \times$ $10^{6} \mathrm{~Pa} / \mathrm{m} ; Z_{w}=4.5 \mathrm{~m}$; and $R_{e}=1000 \mathrm{~m}, 2000 \mathrm{~m}, 3000 \mathrm{~m}$. Figure 16 shows that the larger the distance of boundary to the well is, the longer it requires to see the reflections, and 


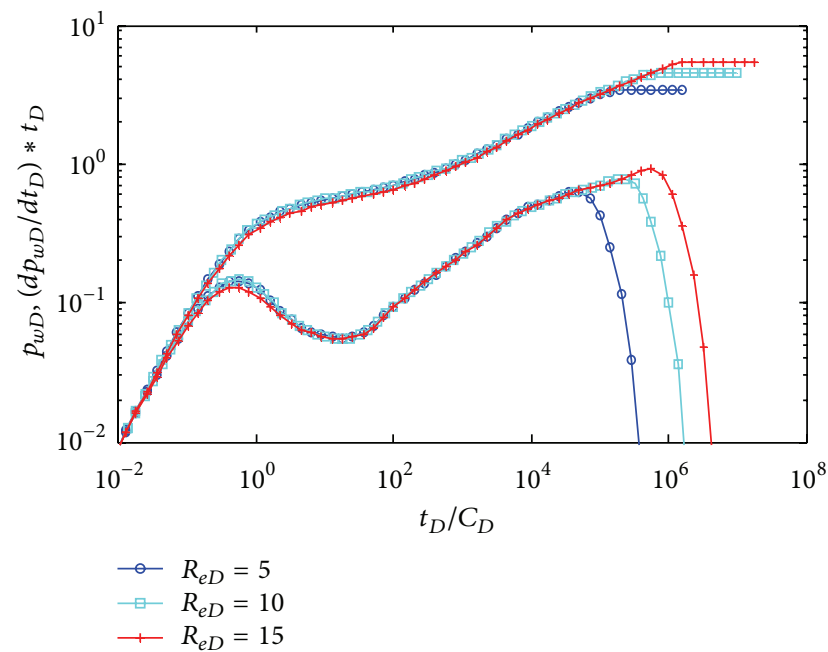

Figure 17: Comparison of dimensionless type curves with different constant-pressure outer boundaries $\left(C_{D}=100 ; S=0 ; L_{D}=5 ; h_{D}=\right.$ $\left.200 ; \alpha_{D}=0.05 ; \lambda_{D}=0.05\right)$.

the stages of pressure reflection in the well test curves move parallel to the right. When the distance of the boundary to the well is small, the upward characteristic caused by stress sensitivity and TPG is not obvious, concealed by boundaries reflect stage. Only when the distance is large enough can the upward characteristic exist obviously. Figure 17 reflects pressure transient in constant-pressure outer boundary. When the pressure reaches the constant-pressure outer boundary, pressure curve tends to be horizontal; pressure derivative curve drops down. Meanwhile, it requires longer time to see the boundary reflections because of the effect of stress sensitivity and TPG.

\section{Field Application}

Pressure test was performed on a horizontal well for the offshore oilfield where the experimental cores come from. The oil production rate is $80.6 \mathrm{~m}^{3} / \mathrm{d}$. The length of horizontal well is $498 \mathrm{~m}$. The effective thickness is $10.8 \mathrm{~m}$. The horizontal well is $8.1 \mathrm{~m}$ far from the bottom boundary. The porosity is $24.6 \%$. The viscosity of crude oil is $1.332 \mathrm{mP}$.s. The volume coefficient is 1.048. The compressibility coefficient is $2.215 \times$ $10^{-3} \mathrm{MPa}^{-1}$.

Using the model in this paper, the matching is carried out to obtain the reservoir parameters as shown in Figure 18. The interpretation results are as follows: horizontal permeability is $14.5 \mathrm{mD}$, vertical permeability and horizontal ratio is 0.093 , wellbore storage is $0.05 \mathrm{~m}^{3} / \mathrm{MPa}$, skin factor is $0.011, \mathrm{TPG}$ is $0.005 \mathrm{MPa} / \mathrm{m}$, and permeability modulus is $0.025 \mathrm{MPa}^{-1}$. As can be seen from Figure 2 and Table 3, when the formation permeability is $14.5 \mathrm{mD}$, the TPG is close to $0.007 \mathrm{MPa} / \mathrm{m}$ and the permeability modulus is nearly $0.024 \mathrm{MPa}^{-1}$. The well testing interpretation results are very close to the experimental data.

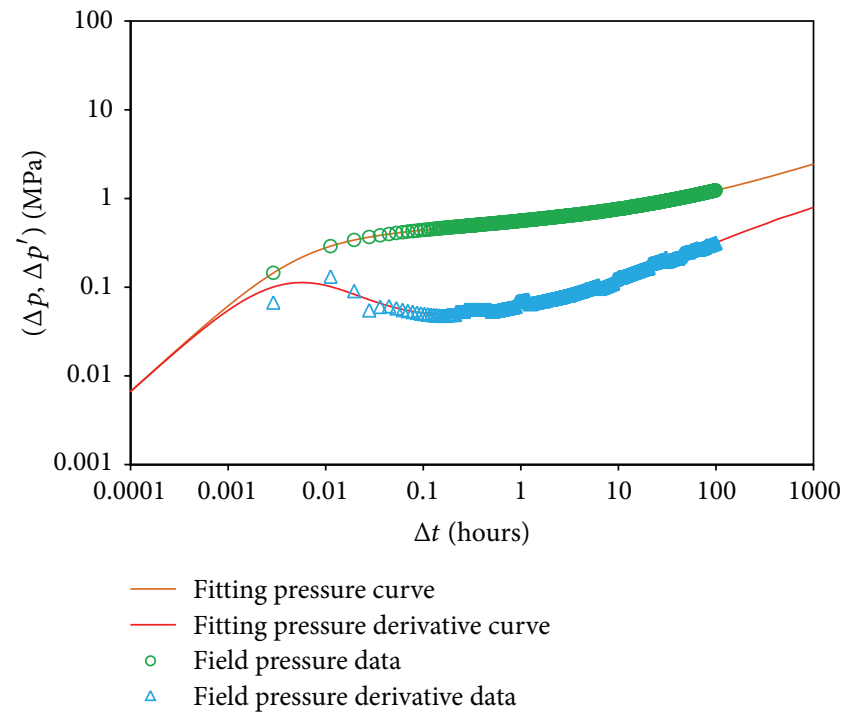

FIGURE 18: Matching curves of well test interpretation.

\section{Conclusion}

(1) With the cores from the a real offshore oilfield in China, the TPG and stress sensitivity were tested. We verified the existence of TPG in irreducible water saturation condition and the permeability stress sensitivity by changing the fluid pressure directly. It shows that TPG and permeability stress sensitivity are relative to the absolute permeability of the cores. The TPG and permeability modulus both increase with the decrease of permeability.

(2) Considering the TPG and permeability modulus, the horizontal well pressure transient mathematical model in an anisotropic low permeability reservoir was established. This model is a nonlinear partial differential equation. FEM is chosen to solve the problem and the detailed solution procedures are discussed. Through comparison with the analytical solution, FEM is verified.

(3) The type curves and derivative type curves of the horizontal well depend on TPG, permeability modulus, well location, well length, wellbore storage, skin factor, and outer boundary. The pressure and pressure derivative curves when considering the stress sensitivity and TPG are different from those based on Darcy's model. The type curves and derivative type curves at early times are not so sensitive to the stress sensitivity and TPG, but, in the late stage, they cause the pressure and pressure derivative curves to shift upwards, resulting in the disappearance of pressure derivative horizon with the value of 0.5 in radial flow stage. In the formation there is additional pressure loss when considering TPG and stress sensitivity.

\section{Appendices}

\section{A. Dimensionless Terms}

Consider

$$
\begin{gathered}
x_{D}=\frac{x}{L}, \quad y_{D}=\frac{y}{L}, \quad z_{D}=\frac{z}{h}, \\
z_{w D}=\frac{z_{w}}{h}, \quad r_{w D}=\frac{r_{w}}{h},
\end{gathered}
$$




$$
\begin{gathered}
t_{D}=\frac{K_{h i} t}{\phi \mu C_{t} r_{w}^{2}}, \quad p_{D}=\frac{K_{h i} h\left(p_{i}-p\right)}{Q \mu B}, \\
L_{D}=\frac{L}{h} \sqrt{\frac{K_{v}}{K_{h}}}, \quad h_{D}=\frac{h}{r_{w}} \sqrt{\frac{K_{h}}{K_{v}}}, \\
C_{D}=\frac{C}{2 \pi h \phi c_{t} r_{w}^{2}}, \quad \alpha_{D}=\frac{Q \mu B}{2 \pi K_{h i} h} \alpha, \\
\lambda_{D}=\frac{2 \pi K_{h i} h L}{Q \mu B} \lambda, \quad \delta_{K D l}=1-\frac{\lambda_{D}}{\left|\nabla p_{D}\right|}, \\
\delta_{K D z}=1-\frac{\lambda_{D}}{L_{D}\left|\nabla p_{D}\right|},
\end{gathered}
$$

where $l=x, y$ and $\lambda_{D z}=\sqrt{K_{h} / K_{v}} \lambda_{D h}$.

\section{B. Solution for Horizontal Well Pressure Analysis Model}

B.1. Finite Element Method. According to Galerkin method [30], we assume the shape function or basic function:

$$
N=\left(N_{1}, N_{2}, \ldots, N_{n}\right) .
$$

The displacement function is

$$
p_{D}=\sum_{j=1}^{n} N_{j} p_{D j}
$$

where $n$ is the number of nodes and $p_{D j}$ is the dimensionless pressure at the node $j$. have

By integrating over the volume of the element, $\Omega_{e}$, we

$$
\begin{aligned}
& \iiint_{\Omega_{e}} N_{j}[ \frac{\partial}{\partial x_{D}}\left(e^{-\alpha_{D} p_{D}} \delta_{K D x} \frac{\partial p_{D}}{\partial x_{D}}\right) \\
&+ \frac{\partial}{\partial y_{D}}\left(e^{-\alpha_{D} p_{D}} \delta_{K D y} \frac{\partial p_{D}}{\partial y_{D}}\right) \\
&\left.+\frac{\partial}{\partial z_{D}}\left(e^{-\alpha_{D} p_{D}} \delta_{K D z} L_{D}^{2} \frac{\partial p_{D}}{\partial z_{D}}\right)\right] d V \\
&=\iiint_{\Omega_{e}}\left(h_{D} L_{D}\right)^{2} N_{j} \frac{\partial p_{D}}{\partial t} d V .
\end{aligned}
$$

With the Green function, we can get

$$
\begin{gathered}
\iiint_{\Omega_{e}} N_{j}\left[\frac{\partial}{\partial x_{D}}\left(e^{-\alpha_{D} p_{D}} \delta_{K D x} \frac{\partial p_{D}}{\partial x_{D}}\right)\right. \\
+\frac{\partial}{\partial y_{D}}\left(e^{-\alpha_{D} p_{D}} \delta_{K D y} \frac{\partial p_{D}}{\partial y_{D}}\right) \\
\left.+\frac{\partial}{\partial z_{D}}\left(e^{-\alpha_{D} p_{D}} \delta_{K D z} L_{D}^{2} \frac{\partial p_{D}}{\partial z_{D}}\right)\right] d V \\
=-\iiint_{\Omega_{e}} e^{-\alpha_{D} p_{D}}\left(\delta_{K D x} \frac{\partial N_{j}}{\partial x_{D}} \frac{\partial p_{D}}{\partial x_{D}}+\delta_{K D y} \frac{\partial N_{j}}{\partial y_{D}} \frac{\partial p_{D}}{\partial y_{D}}\right. \\
\left.+\delta_{K D z} L_{D}^{2} \frac{\partial N_{j}}{\partial z_{D}} \frac{\partial p_{D}}{\partial z_{D}}\right) d V \\
+\iint_{\Gamma_{e}} N_{j} e^{-\alpha_{D} p_{D}} \delta_{K D n} \frac{\partial p_{D}}{\partial n_{D}} d A
\end{gathered}
$$

where

$$
\iint_{\Gamma_{e}} e^{-\alpha_{D} p_{D}} \delta_{K D n} \frac{\partial p_{D}}{\partial n_{D}} d A
$$

$$
\begin{aligned}
= & \iint_{\Gamma_{e}} n_{x} e^{-\alpha_{D} p_{D}} \delta_{K D x} \frac{\partial p_{D}}{\partial x_{D}} d A \\
& +\iint_{\Gamma_{e}} n_{y} e^{-\alpha_{D} p_{D}} \delta_{K D y} \frac{\partial p_{D}}{\partial y_{D}} d A \\
& +\iint_{\Gamma_{e}} n_{z} L_{D}^{2} e^{-\alpha_{D} p_{D}} \delta_{K D z} \frac{\partial p_{D}}{\partial z_{D}} d A .
\end{aligned}
$$

For the inner element, we can get

$$
\begin{gathered}
\iiint_{\Omega_{e}} e^{-\alpha_{D} p_{D}}\left(\delta_{K D x} \frac{\partial N_{j}}{\partial x_{D}} \frac{\partial p_{D}}{\partial x_{D}}+\delta_{K D y} \frac{\partial N_{j}}{\partial y_{D}} \frac{\partial p_{D}}{\partial y_{D}}\right. \\
\left.+\delta_{K D z} L_{D}^{2} \frac{\partial N_{j}}{\partial z_{D}} \frac{\partial p_{D}}{\partial z_{D}}\right) d V \\
+\iiint_{\Omega_{e}}\left(h_{D} L_{D}\right)^{2} N_{j} \frac{\partial p_{D}}{\partial t} d V=0 .
\end{gathered}
$$


The matrix form is

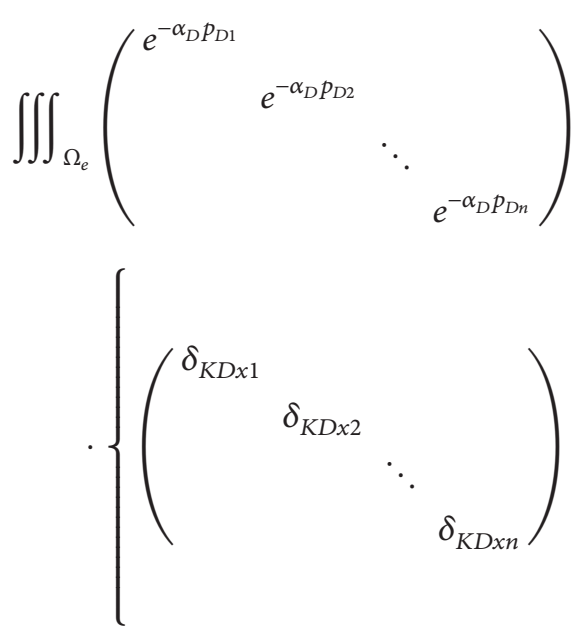

$\left(\begin{array}{c}\frac{\partial N_{1}}{\partial x_{D}} \\ \frac{\partial N_{2}}{\partial x_{D}} \\ \vdots \\ \frac{\partial N_{n}}{\partial x_{D}}\end{array}\right)\left(\begin{array}{llll}\frac{\partial N_{1}}{\partial x_{D}} & \frac{\partial N_{2}}{\partial x_{D}} & \cdots & \frac{\partial N_{n}}{\partial x_{D}}\end{array}\right)$

$+\left(\begin{array}{cccc}\delta_{K D y 1} & & & \\ & \delta_{K D y 2} & & \\ & & \ddots & \\ & & & \delta_{K D y n}\end{array}\right)$

$\left(\begin{array}{c}\frac{\partial N_{1}}{\partial y_{D}} \\ \frac{\partial N_{2}}{\partial y_{D}} \\ \vdots \\ \frac{\partial N_{n}}{\partial y_{D}}\end{array}\right)\left(\begin{array}{llll}\frac{\partial N_{1}}{\partial y_{D}} & \frac{\partial N_{2}}{\partial y_{D}} & \cdots & \frac{\partial N_{n}}{\partial y_{D}}\end{array}\right)$

$+L_{D}^{2}\left(\begin{array}{cccc}\delta_{K D z 1} & & & \\ & \delta_{K D z 2} & & \\ & & \ddots & \\ & & & \delta_{K D z n}\end{array}\right)$

$\left.\left(\begin{array}{c}\frac{\partial N_{1}}{\partial z_{D}} \\ \frac{\partial N_{2}}{\partial z_{D}} \\ \vdots \\ \frac{\partial N_{n}}{\partial z_{D}}\end{array}\right)\left(\begin{array}{llll}\frac{\partial N_{1}}{\partial z_{D}} & \frac{\partial N_{2}}{\partial z_{D}} & \cdots & \frac{\partial N_{n}}{\partial z_{D}}\end{array}\right)\right\}$
$\left(\begin{array}{c}p_{D 1} \\ p_{D 2} \\ \vdots \\ p_{D n}\end{array}\right) d V$

$+\iiint_{\Omega_{e}}\left(h_{D} L_{D}\right)^{2}\left(\begin{array}{c}N_{1} \\ N_{2} \\ \vdots \\ N_{n}\end{array}\right)\left(\begin{array}{llll}N_{1} & N_{2} & \cdots & N_{n}\end{array}\right)$

$$
\left(\begin{array}{c}
\frac{p_{D 1}^{m}-p_{D 1}^{m-1}}{\Delta t_{D}} \\
\frac{p_{D 2}^{m}-p_{D 2}^{m-1}}{\Delta t_{D}} \\
\vdots \\
\frac{p_{D n}^{m}-p_{D n}^{m-1}}{\Delta t_{D}}
\end{array}\right) d V=0 .
$$

Define the following parameters:

$$
\mathbf{B}_{l}=\left(\begin{array}{llll}
\frac{\partial N_{1}}{\partial l_{D}} & \frac{\partial N_{2}}{\partial l_{D}} & \cdots & \frac{\partial N_{n}}{\partial l_{D}}
\end{array}\right),
$$

$$
\mathbf{N}=\left(\begin{array}{c}
N_{1} \\
N_{2} \\
\vdots \\
N_{n}
\end{array}\right)
$$

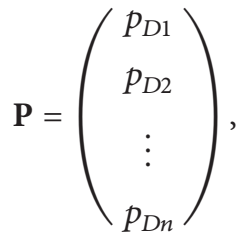

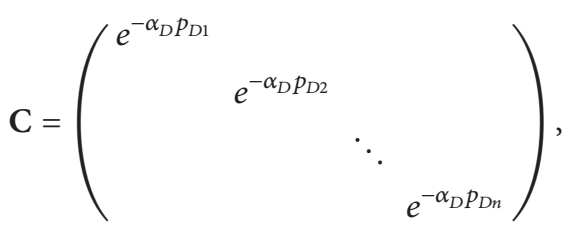

$\mathbf{D}_{l}=\left(\begin{array}{cccc}\delta_{K D l 1} & & & \\ & \delta_{K D l 2} & & \\ & & \ddots & \\ & & & \delta_{K D l n}\end{array}\right)$. 
The equation will be

$$
\begin{gathered}
\iiint_{\Omega_{e}}\left[\mathbf{C}\left(\mathbf{D}_{x} \mathbf{B}_{x}^{T} \mathbf{B}_{x}+\mathbf{D}_{y} \mathbf{B}_{y}^{T} \mathbf{B}_{y}+L_{D}^{2} \mathbf{D}_{z} \mathbf{B}_{z}^{T} \mathbf{B}_{z}\right)\right. \\
\left.+\left(h_{D} L_{D}\right)^{2} \frac{\mathbf{N N}^{T}}{\Delta t_{D}}\right] d V \mathbf{P}^{m} \\
=\iiint_{\Omega_{e}}\left(h_{D} L_{D}\right)^{2} \frac{\mathbf{N N}^{T}}{\Delta t_{D}} d V \mathbf{P}^{m-1} .
\end{gathered}
$$

A simple form will be

$$
\mathbf{K}_{e} \mathbf{P}^{m}=\mathbf{F}_{e}
$$

where

$$
\begin{gathered}
\mathbf{K}_{e}=\iiint_{\Omega_{e}}\left[\mathbf{C}\left(\mathbf{D}_{x} \mathbf{B}_{x}^{T} \mathbf{B}_{x}+\mathbf{D}_{y} \mathbf{B}_{y}^{T} \mathbf{B}_{y}+L_{D}^{2} \mathbf{D}_{z} \mathbf{B}_{z}^{T} \mathbf{B}_{z}\right)\right. \\
\left.+\left(h_{D} L_{D}\right)^{2} \frac{\mathbf{N N}^{T}}{\Delta t_{D}}\right] d V \\
\mathbf{F}_{e}=\iiint_{\Omega_{e}}\left(h_{D} L_{D}\right)^{2} \frac{\mathbf{N N}^{T}}{\Delta t_{D}} d V \mathbf{P}^{m-1} .
\end{gathered}
$$

B.2. Boundary Condition. The uniform flux inner boundary is used to describe the inflow performance of the horizontal well. The wellbore pressure can be considered as the pressure at the position $0.7 \mathrm{~L}$ [22].

For the element including well nodes, the $\mathbf{F}_{e}$ in (B.12) needs to be modified to add a source/sink:

$$
\mathbf{f}_{e}=\iiint_{\Omega_{e}} N_{j} q d V
$$

Use the Delta function to describe the source/sink:

$$
q=\frac{Q}{k} \delta\left(x-x_{0}\right) \delta\left(y-y_{0}\right) \delta\left(z-z_{0}\right),
$$

where $k$ is the element number containing the horizontal well. $\left(x_{0}, y_{0}, z_{0}\right)$ is the horizontal well position coordinate.

The dimensionless form is

$$
\mathbf{f}_{e}=\frac{2 \pi}{k} \iiint_{\Omega_{e}} N_{j}\left(x_{D 0}, y_{D 0}, z_{D 0}\right) d V .
$$

By solving the equation system, the well bore pressure can be obtained in real space without considering the wellbore storage and skin factor. The wellbore storage and skin factor were considered by using discrete numerical Laplace transform method [31] in which the real space well bore pressure can be converted into Laplace space. Then the response of a well with wellbore storage and skin can be obtained using [29]

$$
\bar{p}_{w D}=\frac{s \bar{p}_{D}+S / L_{D}}{s\left(1+C_{D} s\left(s \bar{p}_{D}+S / L_{D}\right)\right)},
$$

where $\bar{p}_{D}$ is the dimensionless pressure without wellbore storage and skin effects (in Laplace space). With the StehfestLaplace numerical inversion method [32], the $p_{w D}$ can be achieved in real space.

\section{Nomenclature}

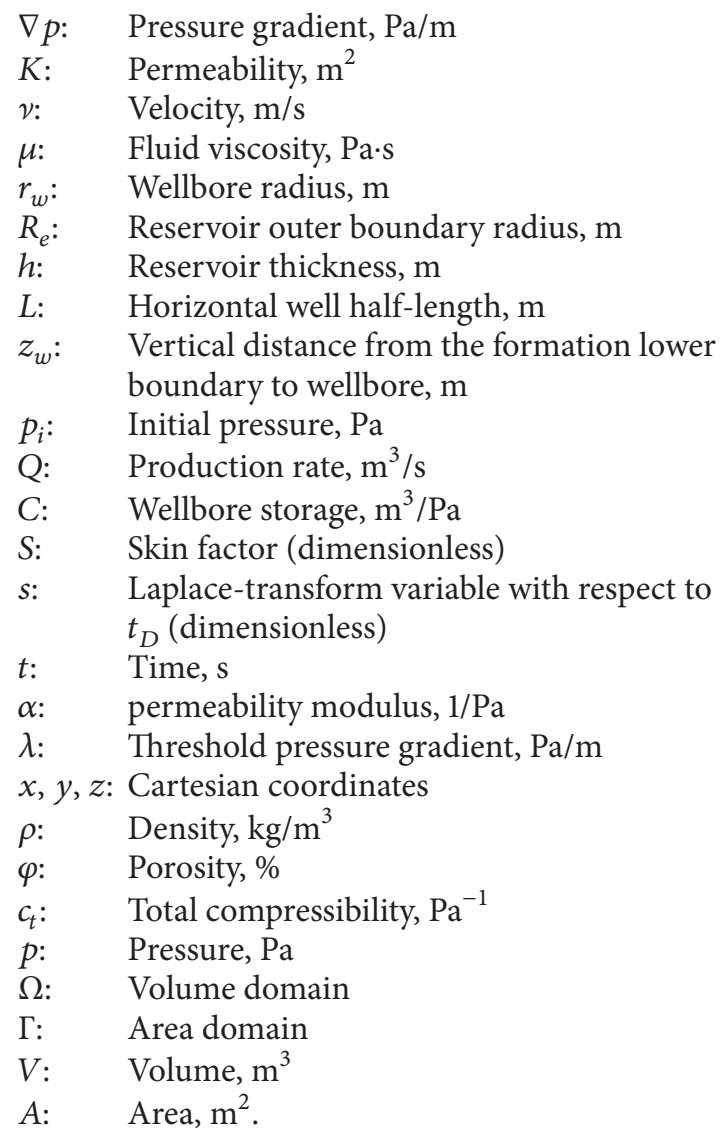

\section{Subscripts and Superscripts}

D: Dimensionless

$i$ : Initial

$h$ : Horizontal direction

$v$ : Vertical direction

-: Laplace

e: Element

$m$ : Time step.

\section{Conflict of Interests}

Jianchun Xu, Ruizhong Jiang, and Teng Wenchao declare that there is no conflict of interests regarding the publication of this paper.

\section{Acknowledgments}

This work is supported by the National Natural Science Foundation of China (Grants nos. are 51174223 and 51374227), the Fundamental Research Funds for the Central University under 14CX06087A, the Graduate Innovation Fund of China University of Petroleum (East China) under CX-1210 and YCX2014017, and the National 12th Five-Year Plan under 2011ZX05013-006 and 2011ZX05051. 


\section{References}

[1] B. Zeng, L. Cheng, and C. Li, "Low velocity non-linear flow in ultra-low permeability reservoir," Journal of Petroleum Science and Engineering, vol. 80, no. 1, pp. 1-6, 2011.

[2] F. Hao, L. S. Cheng, O. Hassan, J. Hou, C. Z. Liu, and J. D. Feng, "Threshold pressure gradient in ultra-low permeability reservoirs," Petroleum Science and Technology, vol. 26, no. 9, pp. 1024-1035, 2008.

[3] X. W. Wang, M. Z. Yang, P. Y. Sun, and W. X. Liu, "Experimental and theoretical investigation of nonlinear flow in low permeability reservoir," Procedia Environmental Sciences, vol. 11, pp. 1392-1399, 2011.

[4] Q. Lei, W. Xiong, and J. Yuan, "Behavior of flow through lowpermeability reservoirs," in Proceedings of the Europec/EAGE Conference and Exhibition, Society of Petroleum Engineers, 2008.

[5] X. Wei, L. Qun, G. Shusheng, H. Zhiming, and X. Hui, "Pseudo threshold pressure gradient to flow for low permeability reservoirs," Petroleum Exploration and Development, vol. 36, no. 2, pp. 232-236, 2009.

[6] A. Prada and F. Civan, "Modification of Darcy's law for the threshold pressure gradient," Journal of Petroleum Science and Engineering, vol. 22, no. 4, pp. 237-240, 1999.

[7] L. Gavin, "Pre-Darcy flow: a missing piece of the improved oil recovery puzzle?" in Proceedings of the SPE/DOE Symposium on Improved Oil Recovery, SPE-89433-MS, Society of Petroleum Engineers, Tulsa, Oklahoma, April 2004.

[8] P. Basak, "Non-Darcy flow and its implications to seepage problems," Journal of the Irrigation and Drainage Division, vol. 103, no. 4, pp. 459-473, 1977.

[9] W. Zhu, H. Song, X. Huang, X. Liu, D. He, and Q. Ran, "Pressure characteristics and effective deployment in a water-bearing tight gas reservoir with low-velocity non-darcy flow," Energy \& Fuels, vol. 25, no. 3, pp. 1111-1117, 2011.

[10] Y. Hu, X. Li, Y. Wan et al., "Physical simulation on gas percolation in tight sandstones," Petroleum Exploration and Development, vol. 40, no. 5, pp. 621-626, 2013.

[11] Q. Xu, X. Liu, Z. Yang, and J. Wang, “The model and algorithm of a new numerical simulation software for low permeability reservoirs," Journal of Petroleum Science and Engineering, vol. 78, no. 2, pp. 239-242, 2011.

[12] D.-Y. Yin and H. Pu, "Numerical simulation study on surfactant flooding for low permeability oilfield in the condition of threshold pressure," Journal of Hydrodynamics, vol. 20, no. 4, pp. 492-498, 2008.

[13] H. Liu, H. Zhang, and Z. Wang, "Doubling model for lower permeability formation with hydraulic fracture," Petroleum Science and Technology, vol. 29, no. 9, pp. 898-905, 2011.

[14] J.-J. Guo, S. Zhang, L.-H. Zhang, H. Qing, and Q.-G. Liu, "Well testing analysis for horizontal well with consideration of threshold pressure gradient in tight gas reservoirs," Journal of Hydrodynamics, vol. 24, no. 4, pp. 561-568, 2012.

[15] I. Palmer and J. Mansoori, "How permeability depends on stress and pore pressure in coalbeds: a new model," SPE Reservoir Evaluation \& Engineering, vol. 1, no. 6, 1998.

[16] H. Ruistuen, L. W. Teufel, and D. Rhett, "Influence of reservoir stress path on deformation and permeability of weakly cemented sandstone reservoirs," SPE Reservoir Evaluation and Engineering, vol. 2, no. 3, pp. 266-272, 1999.

[17] J. C. Lorenz, "Stress-sensitive reservoirs," Journal of Petroleum Technology, vol. 51, no. 1, pp. 61-63, 1999.
[18] S. Chen, H. Li, Q. Zhang, and D. Yang, "A new technique for production prediction in stress-sensitive reservoirs," Journal of Canadian Petroleum Technology, vol. 47, no. 3, pp. 49-54, 2008.

[19] S. A. Sonnenberg and A. Pramudito, "Petroleum geology of the giant Elm Coulee field, Williston Basin," AAPG Bulletin, vol. 93, no. 9, pp. 1127-1153, 2009.

[20] H.-X. Wang, G. Wang, Z.-X. J. Chen, and R. C. K. Wong, "Deformational characteristics of rock in low permeable reservoir and their effect on permeability," Journal of Petroleum Science and Engineering, vol. 75, no. 1-2, pp. 240-243, 2010.

[21] F. Ma, S. He, H. Zhu, Q. Xie, and C. Jiao, "The effect of stress and pore pressure on formation permeability of ultra-lowpermeability reservoir," Petroleum Science and Technology, vol. 30, no. 12, pp. 1221-1231, 2012.

[22] A. J. Rosa and R. D. S. Carvalho, "A mathematical model for pressure evaluation in an infinite-conductivity horizontal well," SPE Formation Evaluation, vol. 4, no. 4, pp. 559-15967, 1989.

[23] S. Knut, S. C. Lien, and B. T. Haug, "Troll horizontal well tests demonstrate large production potential from thin oil zones," SPE Reservoir Engineering, vol. 9, no. 2, pp. 133-139, 1994.

[24] M. C. Ng and R. Aguilera, "Well test analysis of horizontal wells in bounded naturally fractured reservoirs," in Proceedings of the Annual Technical Meeting, Petroleum Society of Canada, 1994.

[25] E. Ozkan and R. Raghavan, "New solutions for well-testanalysis problems. Part 1. Analytical considerations," SPE Formation Evaluation, vol. 6, no. 3, pp. 359-368, 1991.

[26] H. Zhan, L. V. Wang, and E. Park, "On the horizontal-well pumping tests in anisotropic confined aquifers," Journal of Hydrology, vol. 252, no. 1-4, pp. 37-50, 2001.

[27] E. Park and H. Zhan, "Hydraulics of a finite-diameter horizontal well with wellbore storage and skin effect," Advances in Water Resources, vol. 25, no. 4, pp. 389-400, 2002.

[28] Y. Saad, Iterative Methods for Sparse Linear Systems, SIAM, Philadelphia, Pa, USA, 2003.

[29] X. P. Li, L. H. Zhang, and Q. G. Liu, Well Test Analysis Method, Petroleum Industry Press, 2009.

[30] O. C. Zienkiewicz, The Finite Element Method Set, McGrawHill, London, UK, 1977.

[31] J. Yao and Z. S. Wang, Theory and Method for Well Test Interpretation in Fractured-Vuggy Carbonate Reservoirs, China University of Petroleum Press, Dongying, China, 2008.

[32] D. K. Tong and Q. L. Chen, "A note on the Stehfest Laplace numerical inversion method," Acta Petrolei Sinica, vol. 22, no. 6, 2001. 


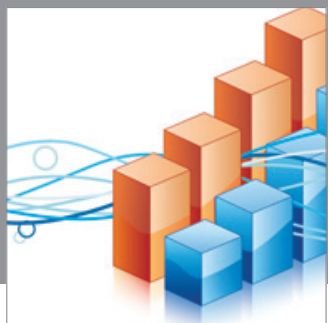

Advances in

Operations Research

mansans

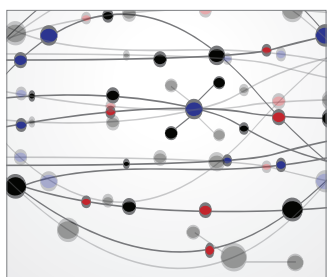

The Scientific World Journal
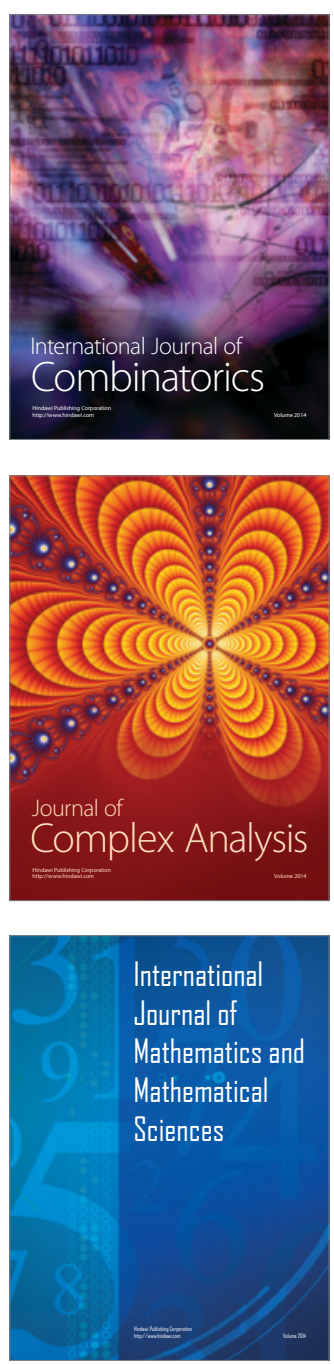
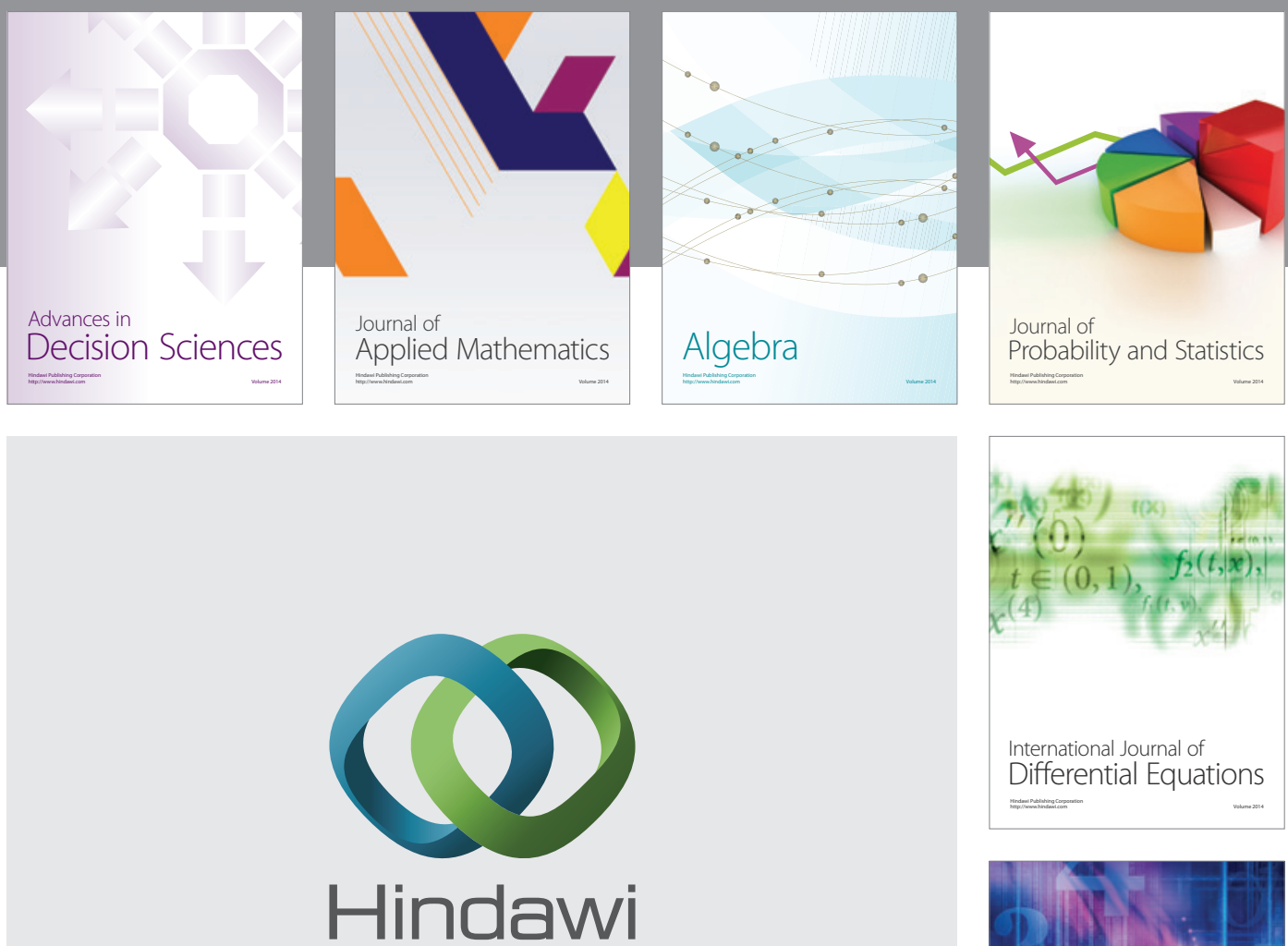

Submit your manuscripts at http://www.hindawi.com
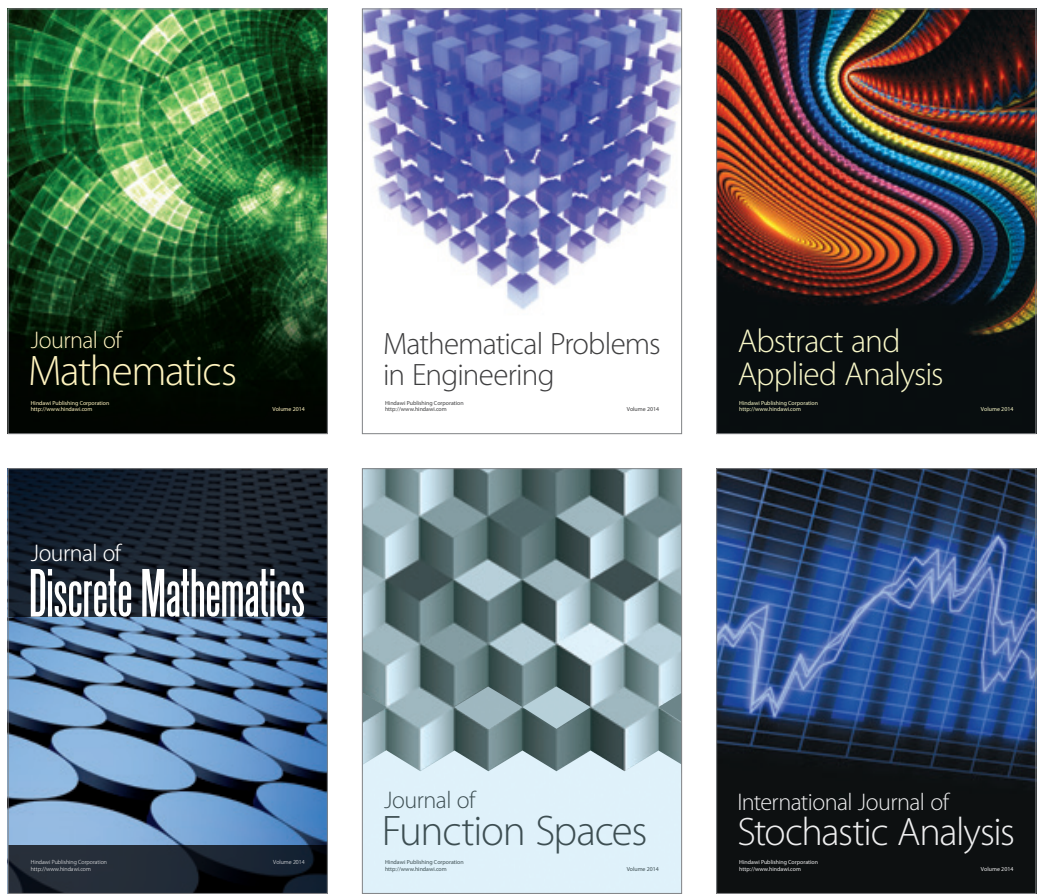

Journal of

Function Spaces

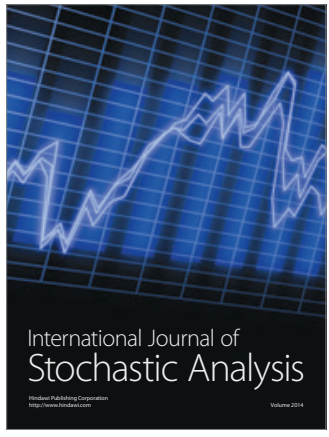

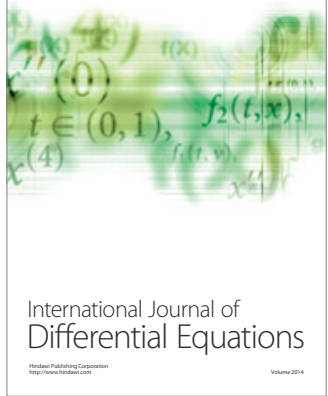
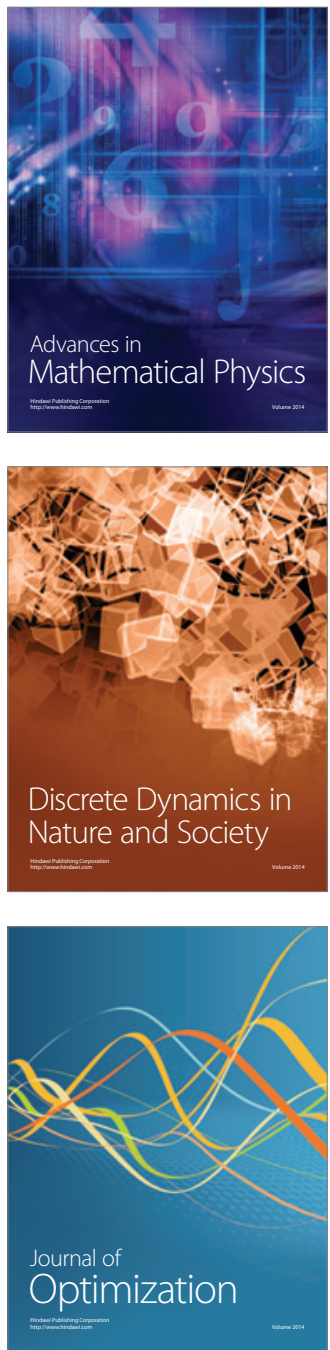